\title{
Efficiencies of Horizontal and Vertical Baffle Mixers
}

\author{
J. I. Obianyo ${ }^{a^{*}}$, J. C. Agunwamba ${ }^{b}$ \\ ${ }^{a}$ Department of Civil Engineering, Michael Okpara University of Agriculture, Umudike, Abia State, Nigeria \\ ${ }^{b}$ Department of Civil Engineering, University of Nigeria, Nsukka, Enugu State, Nigeria
}

\section{Abstract}

Efficiencies of sedimentation tanks with horizontal and vertical baffle mixers were studied, compared, and also to determine the optima values of factors of clarification in the sedimentation tanks. These are the discharge, basin baffle spacing and dosing factors, thereby comprises three factors at five levels for a $5 \mathrm{k}$ factorial design model. $2.0 \mathrm{mg} / \mathrm{l}$ of clay solution was introduced into the basin at discharge rates of $48.75 \mathrm{ml} / \mathrm{s}, 55.07 \mathrm{ml} / \mathrm{s}, 60.34 \mathrm{ml} / \mathrm{s}, 62.45 \mathrm{ml} / \mathrm{s}$ and $63.27 \mathrm{ml} / \mathrm{s}$ respectively. Alum solution was introduced as coagulant at the inlet of the basin, samples were collected both from the basin and the outlet and concentrations of flocs were measured. Plots of variation of total outlet and average outlet floc with dosing rates for horizontal and vertical mixers show that vertical mixers are better only at discharge of $48.75 \mathrm{ml} / \mathrm{s}$, but horizontal mixers are better at $55.05 \mathrm{ml} / \mathrm{s}, 60.34 \mathrm{ml} / \mathrm{s}, 62.45$ $\mathrm{ml} / \mathrm{s}$ and $63.27 \mathrm{ml} / \mathrm{s}$. Variation of grand total floc with dosing rates is also in favour of horizontal mixers. Plots of outlet floc against dosing rates at $48.75 \mathrm{ml} / \mathrm{s}$ discharge show that horizontal mixer spaced at $100 \mathrm{~mm}$ is better with maximum sediment/floc of $333 \times 10^{-4} \mathrm{~g}$ at a dosing rate of $0.55 \mathrm{ml} / \mathrm{s}$, at $55.07 \mathrm{ml} / \mathrm{s}$ discharge vertical mixer is better with $250 \mathrm{~mm}$ spacing giving maximum sediment of $985 \times 10^{-4} \mathrm{~g}$ at a dosing rate of $0.95 \mathrm{ml} / \mathrm{s}$. For $60.34 \mathrm{ml} / \mathrm{s}$ discharge, horizontal mixer is better at 250 $\mathrm{mm}$ spacing with maximum sediment of $307 \times 10^{-4} \mathrm{~g}$ at $0.75 \mathrm{ml} / \mathrm{s}$ dosing rate. In the case of 62.45 $\mathrm{ml} / \mathrm{s}$ discharge, horizontal mixer at a spacing of $300 \mathrm{~mm}$ is better with a maximum deposit of $335 \times$ $10^{-4} \mathrm{~g}$ at a dosing rate of $0.95 \mathrm{ml} / \mathrm{s}$, and for discharge of $63.27 \mathrm{ml} / \mathrm{s}$, horizontal mixer is better at 150 $\mathrm{mm}$ spacing having a maximum sediment of $715 \times 10^{-4} \mathrm{~g}$ for a dosing rate of $0.35 \mathrm{ml} / \mathrm{s}$. Response surface methodology (RSM) presented by Montgomery, 2008 was further used for the analysis of data in this study for more reliable inference because it optimized the responses of these three variables. It was observed that for the vertically placed baffles, the stationary points of response surface for discharge rate, baffle spacing and dosing rate are $80.56762847 \mathrm{ml} / \mathrm{s}, 100.00000 \mathrm{~mm}$ and $0.04965779 \mathrm{ml} / \mathrm{s}$, while for horizontally placed baffles, it was $70.636018 \mathrm{ml} / \mathrm{s}, 332.864704 \mathrm{~mm}$ and $1.402526 \mathrm{ml} / \mathrm{s}$, however, these results indicate that horizontally placed baffle mixers are better than vertically placed baffle mixers.
\end{abstract}

\section{Keywords:}

Efficiencies;

Horizontal;

Vertical;

Baffle Mixers;

Comparison.

Article History:

Received: 29 February 2019

Accepted: 26 May 2019

\section{1- Introduction}

This study compared the efficiencies of horizontal and vertical baffle mixers in sedimentation basins. It also determined the optima values for the three variables considered in this work, discharge rates, dosing rates and baffle spacing respectively. The objective of this work is to assist in making timely decision in the recommendation of a better configuration of baffle mixers in the treatment of wastewater. Baffles are needed to stop the swirl in a mixing tank. Almost all impellers rotate in the clockwise or counter- clockwise direction. Without baffles, the tangential velocities coming from any impeller(s) causes the entire fluid mass to spin. It may look good from the surface seeing that vortex all the way down to the impeller, but this is more like a centrifuge than a mixer. In order to achieve the objective of removing fine discrete particles in sedimentation tanks, baffles are used to enhance flocculation. Solids removal is

\footnotetext{
* CONTACT: Obianyo.jude@ mouau.edu.ng

DOI: http://dx.doi.org/10.28991/esj-2019-01176
}

(C) 2019 by the authors. Licensee ESJ, Italy. This is an open access article under the terms and conditions of the Creative Commons Attribution (CC-BY) license (https://creativecommons.org/licenses/by/4.0/). 
probably the main aim of water purification in sedimentation tanks. The performance of these sedimentation tanks is directly affected by the filtration basin [1]. Sedimentation tanks are divided into two main categories, namely primary and secondary sedimentation tanks. Primary sedimentation tanks have low influent concentrations, their flow field is not much influenced by the concentration field and buoyancy effects can be negligible. Secondary sedimentation tanks on the other hand have higher influent concentrations [2]. In a study of secondary sedimentation basin design, with a 2Dimensional Computational Fluid Dynamics (CFD) model, Settler CAD, used as a basic 3-Dimensional full-scale sedimentation basin, Metcalf and Eddy (2003) showed that although the baffle could significantly reduce the effluent suspended solids (ESS) concentrations while the sedimentation basin was under-loaded, it did not increase the flux rating (or capacity) of these basins [3]. Qualitatively, baffle positions have significant effect on the flow patterns, suspended solids concentration and solids removal efficiency [1]. Crosby (1984) used an additional baffle at mid-radius extending from the floor upwards to the mid depth, and observed a reduction of $38 \%$ in effluent concentration [4]. Placing of an intermediate baffle, installed close to the middle of the clarifier and extending from the floor upward to one-third depth, had no significant effect on the efficiency [5], but a change in the arrangement of inlet feed could allow a device to handle higher volumes by maintaining the flow conditions that improve sedimentation [6].

Reynolds and Froude numbers must be considered together in studies concerning flows in sedimentation tanks, and at high Reynolds number, the flow fields and baffle positions were not affected by the inlet Froude numbers [7]. Dynamic mixers are qualified as efficient vessels for mixing in processes accompanied by mass, momentum and heat transfer and chemical reaction. In recent researches, there has been an increasing interest in the development of alternative designs for improvements of key elements, such as geometry of baffles, mixer vessels, impellers, operational parameters of mixers and impellers, etc. [8]. Sedimentation tanks are important components of any water purification plant, and account for approximately a third of the infrastructure cost [9]. Their task is to remove suspended particles from the flow field, so their efficiency affects the performance of other parts of the plant [10]. Sedimentation tank (ST) usage can be classed into two main categories: (i) Waste-Water Treatment Plants (WWTPs) and (ii) Water Treatment Plants (WTPs). WWTPs include Primary Settling Tanks (PSTs) and Secondary Settling Tanks (SSTs). Primary settling tanks (PSTs) are designed to dissipate kinetic energy, reduce the overall flow velocity and to let solids settle [11]. Typically, secondary settling tanks (SSTs) are located after mixers in wastewater treatment plants (WWTPs) where flocculation and coagulation processes occur.

In terms of their internal functioning, ST can be divided into four areas: (i) inlet zone, (ii) settling zone, (iii) sludge zone, and (iv) outlet zone [12]. At the tank exit, the solids loading (SL, solids flux in the outflow [13] is the design parameter that defines the tank capacity. Sediment deposition and thus tank efficiency, is a function of energy dissipation in the tank, which is in turn related to maximal flow rates. Probably the least efficient ST is one in which a jet formed at the inlet is routed directly to the tank exit without appreciably lowering its inlet (i.e. maximum) velocity. This pattern would, additionally, induce circulations that would maintain sediments in suspension. These "dead" zones decrease the tanks effective volume, and decrease tank performance if they are accompanied by intense mixing and turbulence leading to sediment re-suspension (e.g., [14]). There are a number of comprehensive studies on baffled tanks that investigate their hydraulic efficiency $[15,16]$. Bretscher et al. (1992) considered a rectangular clarifier and showed that an intermediate (where intermediate refers to location along the tank length) baffle on the base of the tank, transverse to the main flow direction, influences the flow field and can improve efficiency [17]. Krebs (1991) and Krebs et al. (1995) focused on the flow field and the potential energy of incoming flows. His analysis was based on a $2 \mathrm{D}$ hydrodynamics code validated by laboratory results. The model was applied to evaluate various inlet arrangements and bottom currents. To enhance sediment settlement on the tank bottom, he suggested placement of an inlet baffle [2, 18].

Numerical models of flow patterns, sediment mixing rate and turbulence characteristics in STs have been reported. Celik et al. (1985) and Adams and Rodi (1990) used the $k-\varepsilon$ turbulence closure model [19, 20]. Lyn et al. (1992) showed that the flow field depends on the particle density entering the tank and the entrance geometry [21].

Tamayol et al. (2008) examined the tank performance using the particle-tracking method. They observed a large circulation zone and concluded that a baffle placement that disturbed this zone resulted in improved tank performance [9]. Goula et al. (2008) indicated that the baffle height is important, as it can decrease the inlet recirculation zone and increase sedimentation [11]. Liu et al. (2009) used laser Doppler velocimetry to conduct flow-field measurements, accompanied by numerical simulation of the flow field to evaluate the effect of inlet height on sedimentation efficiency [22]. Effects of baffle height and position were not considered. The effect of baffle angles and positions were examined using a 2D model [23] applied to a small-scale, 2-m long laboratory setup [24-26]. Right-angled (to the tank base) baffles were most favorable for sedimentation. In addition, it was concluded that, to achieve high settling performance, the baffle should be somewhere close to the inlet. However, the effects of baffle height and optimal baffle configuration were not considered. 


\section{2- Materials and Method}

\section{2-1- Sources of Data}

Primary data was the main source of data for this study, of course this is an experimental research so that a distorted model of scale ratio 1:8 to that of Razmi et al. (2013) [27] was constructed and used for the experiment. After the experiment, data was generated and was analyzed statistically using response surface methodology (RSM).

\section{2-2- Parameters of Interest}

The parameters of in this study are;

a. Optimum baffle spacing from the inlet ( $\mathrm{mm}$ )

b. Optimum discharge rate $(\mathrm{ml} / \mathrm{s})$

c. Optimum dosing rate $(\mathrm{ml} / \mathrm{s})$

d. Flocs inlet concentrations (g)

e. Flocs outlet concentrations (g)

\section{2-3- Samples and Sampling Techniques}

A $1: 8$ scale distorted model sedimentation tank geometrically similar to the one used by Razmi et al. (2013) [27] in their research was used in conducting the experiment, with dimensions $1.00 \mathrm{~m}$ long, $0.30 \mathrm{~m}$ deep and $0.20 \mathrm{~m}$ wide. The materials for this study include alum solution, clay soil, distilled water and horizontal and vertical baffle mixers with baffles spaced at $100 \mathrm{~mm}, 150 \mathrm{~mm}, 200 \mathrm{~mm}, 250 \mathrm{~mm}$ and $300 \mathrm{~mm}$ respectively. The specific gravity of clay soil passing the No.300 BS sieve (i.e. $63 \mu \mathrm{m}$ ) was determined and used to prepare the turbid water for this study by dissolving 1000 $\mathrm{g}$ of the pre-treated soil in $0.50 \mathrm{~m}^{3}$ of distilled water (i.e. $2.0 \mathrm{mg} / \mathrm{l}$ ) after which a dispersing agent was added to prevent flocculation. Essentially, the pre-treatment was meant to remove organic matter content from the soil. The dissolved clay water was introduced into the clay solution tank by opening the control valve. The clay solution tank is a cylindrical tank of $0.85 \mathrm{~m}$ diameter, $1.00 \mathrm{~m}$ depth, with volume capacity of $0.567 \mathrm{~m}^{3}$. The content was allowed to settle for 15 minutes after which it was gently mixed for 10 minutes in order to obtain a homogeneous clay solution before discharge into the sedimentation tank with the baffles revolving at 2 revolutions per minute (rpm).

\section{2-4- Experimental Setup and Procedure}

The equipment is made up of the following components; constant head refilling tank of dimensions 0.40 m diameter and $0.6 \mathrm{~m}$ depth which contains clay solution of $2.0 \mathrm{mg} / \mathrm{l}$ concentration; the dossator; detachable sedimentation tanks of dimensions $1.0 \mathrm{~m}$ length, $0.30 \mathrm{~m}$ wide and $0.70 \mathrm{~m}$ depth of capacity $0.210 \mathrm{~m}^{3}$, adapted for the fixing of both vertical and horizontal baffles, detachable baffles at 100, 150, 200, 250 and $300 \mathrm{~mm}$ spacing respectively, alum solution container and the pumping machine for supply of clay solution into the sedimentation tank. The experimental set up is shown in Figure 1. Clay solution was injected into the baffle tank when the dosing pump was set at zero, a 10ml sample of solution was collected and subjected to fine analysis using the pipette method. This a lengthy and painstaking process, described in detail in [28] to determine the quantity of floc/sediments in microns $(\mu \mathrm{m})$ contained in the solution, which served as the control experiment.

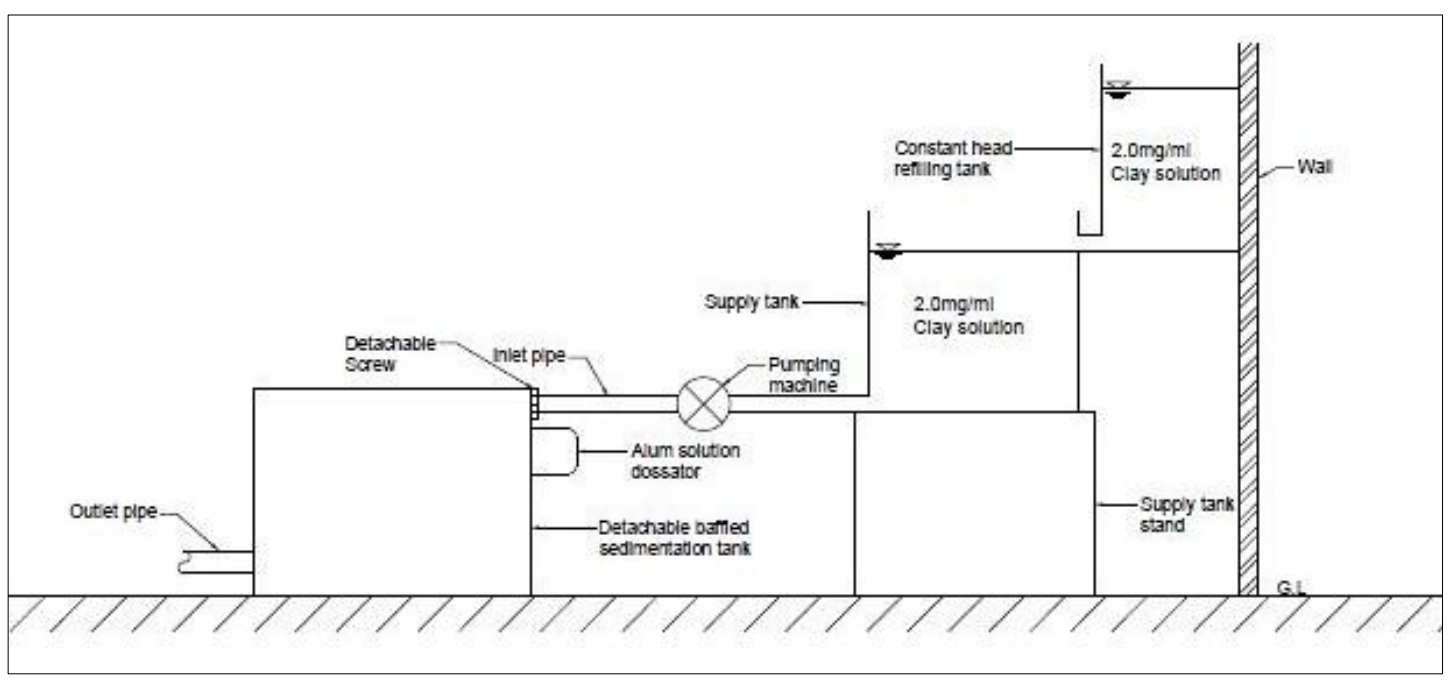

Figure 1. Schematic diagram for the efficiencies of horizontal and vertical baffle mixers. 


\section{2-5- Laboratory Analysis}

In the control experiment, $0.105 \mathrm{~m}^{3}$ containing $102 \mathrm{~g}$ weight $\left(W_{b}\right)$ of the fine particles was made up to $500 \mathrm{ml}$ with distilled water and placed in a constant temperature bath. When the suspension had reached the temperature of the bath it was taken out, shaken to disperse the particles and replaced in the bath. A stop watch was started immediately the suspension was replaced.

After 4 minutes a 10-ml sample of the suspension was taken by pipette from a depth of $100 \mathrm{~mm}$ and the weight of the solids in the sample found $\left(W_{D}\right)$. A correction was made for the weight of the dispersing agent (sodium hexametaphosphate) in the suspension. To do this a separate solution of the dispersing agent was tested at the same time in the same manner. The whole procedure was repeated after 45 minutes and again after 7 hours. From Stoke's law the velocity of the particles is given by the expression;

$$
v=K D^{2}
$$

Where $K$ is a constant equal to;

$$
\left(\gamma_{s}-\gamma_{w}\right) / 18 \mu_{w}
$$

Where $\gamma_{s}$ and $\gamma_{w}$ are the weights of the fine particles and water and $\mu_{w}$ is the dynamic viscosity of water. After time $t_{1}$ all the particles of a certain size $D_{l}$ will have settled from the surface to a depth of $100 \mathrm{~mm}$. any particles larger than size $D_{I}$ will have sunk below the $100 \mathrm{~mm}$ mark in the suspension. The velocity of particle size $D_{l}$ can therefore be calculated since they have moved a distance of $100 \mathrm{~mm}$ in known time $t_{1}$, i.e.

$$
\begin{aligned}
& v=h / t_{1} \\
& K D_{1}^{2}=h / t_{1} \\
& D_{1}^{2}=h / K t_{1}
\end{aligned}
$$

As $h, t_{l}$ and $K$ are known, the maximum grain size $D_{l}$, at depth $100 \mathrm{~mm}$ after $t_{l}$ can be calculated. Since all smaller sizes than $D_{l}$ at this depth will be present in the same concentration as they were in the original suspension.

Percentage of particles less than size $D_{l}$ in original solution $N$;

$$
N=\left[\left(w_{D_{1}} / 10\right) /\left(w_{b} / 500\right)\right] \times 100
$$

Where $w_{D_{1}} / 10$ is weight of solids per $\mathrm{ml}$ at depth $100 \mathrm{~mm}$ after time $\mathrm{t} ; w_{b} / 500$ is the weight of solids per $\mathrm{ml}$ in original suspension.

Clay solution was further injected into the sedimentation tank using a control valve and the dossator valve opened to supply alum solution into the sedimentation tank at the rate of $0.15,0.35,0.55,0.75$ and $0.95 \mathrm{ml} / \mathrm{s}$ at 60 seconds intervals, while the rate of discharge from the sedimentation tank was measured at 48.75, 55.07, 60.34, 62.45 and $63.27 \mathrm{ml} / \mathrm{s}$ respectively at 60 seconds intervals also. At each dose of alum, sample was collected from the tank to determine the concentration of the clay solution after injection into the sedimentation tank $c_{i}$. Another sample was also collected at the outlet to determine the concentration of the clay solution $c_{0}$ using the method and procedure described above. The rate of flow and efficiency of the system were determined from the relationships;

$$
Q=v / t
$$

Where $Q=$ Rate of discharge $(\mathrm{ml} / \mathrm{s}) ; v=$ Volume of sample collected from the outlet $(\mathrm{ml}) ; t=$ Time $(\mathrm{s})$.

$$
E=\left(\frac{c_{0}-c_{1}}{c_{0}}\right) \times 100 \%
$$

Where $E=$ Efficiency; $c_{0}=$ Concentration of the clay solution at the outlet; $c_{i}=$ Concentration of the clay solution after injection into the sedimentation tank.

The data generated was analyzed using the response surface methodology (RSM) presented by Montgomery (2008) [29] and the software used was R Core Team (2017) Statistical software [30]. The model was used to compare the efficiencies of horizontal and vertical baffle mixers and determination of the optimum baffle spacing, discharge rates and dosing rates for both horizontal and vertical baffle mixers.

\section{2-6- Statistical Analysis}

Factorial experiments are employed in all fields of life such as agricultural science, biology, medicine and the 
physical sciences. Experiments are usually carried out by researchers either to discover something about a particular process or to compare the effects of several factors on responses. Factorial experiment is therefore a crossed factor design that usually involves several factors and it is such that every possible combination of the factor is included, observed or examined. Factorial experiments permit the analyses of a number of factors with the same precision (e.g., individual and joint effects) as if the entire experiment had been devoted to the study of only one factor.

Some notable factorial experiments are as follows;

$2^{\mathrm{k}}$ factorial experiments - This involves $\mathrm{k}$ factors each at two levels.

$3^{\mathrm{k}}$ factorial experiment - This involves $\mathrm{k}$ factors each at three levels. $\mathrm{B}^{\mathrm{k}}$ factorial experiment - This involves $\mathrm{k}$ factors each at B levels. Factorial designs are widely used in experiments involving several factors where it is necessary to study the joint effect of the factors on a response. There are several special cases of the general factorial design are widely used in research work and also because they form basis of the designs of considerable practical value. The most important of these special cases is that of $\mathrm{k}$ factors, each at only two levels. These levels may be quantitative, such as two values of temperature, pressure, or time or they may be qualitative, such as two machines, two operators, the "high" and "low", levels of factor, or perhaps the presence and absence of a factor. Considering this case, we considered 3factors at 5 levels each making a 5k factorial design. The discharge factors at $(48.75,55.07,60.34,62.45$ and 63.27$)$, the baffle spacing factors at [B1(100), B2(150), B3(200), B4(250) and B5(300)] and the dosing factors at $(0.15,0.35$, $0.55,0.75$ and 0.95$)$,

The general model is given:

$$
y_{i j k}=\beta_{0}+\beta_{1} x_{1}+\beta_{2} x_{2}+\beta_{3} x_{3}+\beta_{12} x_{1} x_{2}+\beta_{13} x_{1} x_{3}+\beta_{123} x_{1} x_{2} x_{3}+\beta_{23} x_{2} x_{3}+\beta_{11} x_{1}^{2}+\beta_{22} x_{2}^{2}+\beta_{33} x_{3}^{2}+\varepsilon_{i j k}
$$

Response surface methodology (RSM) used in this work, is a collection of mathematical and statistical techniques that are useful for the modeling and analysis of problems in which a response of interest is influenced by several variables and the objective is to optimize these responses. For example, suppose that an engineer wishes to find the levels of the three design factors such as discharge $\left(x_{1}\right)$, dosing rates $\left(x_{2}\right)$, and baffle spacing $\left(x_{3}\right)$ as discussed in the above factorial experiment that maximize the response $(y)$ of the process. The process response is a function of the levels of discharge, dosing rates and baffle spacing;

$$
y=f\left(x_{1}, x_{2}, x_{3}\right)+\varepsilon
$$

Where $\varepsilon$ represents the noise or error observed in the response $y$. If we denote the expected responses by:

$$
E(y)=f\left(x_{1}, x_{2}, x_{3}\right)=\eta
$$

Then the surface represented by

$$
\eta=f\left(x_{1}, x_{2}, x_{3}\right)
$$

A response surface is fitted as an extension of linear model algorithm and works almost exactly like that. However, the model formula for response surface must make use of the first-order, two-way interaction, pure quadratic or secondorder models where the first-order model in Equation 10 is given by:

$$
y_{i j k}=\beta_{0}+\beta_{1} x_{1}+\beta_{2} x_{2}+\beta_{3} x_{3}+\varepsilon_{i j k}
$$

\section{3- Results and Discussion}

The interpretation follows the same line as that of the horizontal. However, the horizontal stationary point seems to be better than that of the vertical. Plots of variation of total and average floc with dosing rates indicate that vertically spaced baffles are better at low discharges as can be seen in Figure 2 at $48.75 \mathrm{ml} / \mathrm{s}$ flow rate. The trend changed at flows of $55.07 \mathrm{ml} / \mathrm{s}, 60.34 \mathrm{ml} / \mathrm{s}, 62.45 \mathrm{ml} / \mathrm{s}$ and $63.27 \mathrm{ml} / \mathrm{s}$ in Figures 3-6 in which better performances were experienced from the horizontally spaced baffle tanks. Figure 7 is a plot of the variation of grand total weight of floc generated with dosing rates from the two systems, and this plot is an indication that horizontally spaced baffle tanks perform better than vertically spaced baffle tanks. Table 6 summarized the results in Tables 1 to 5 , it shows that at discharge of $48.75 \mathrm{ml} / \mathrm{s}$, horizontal mixers are better with maximum sediment deposition of $333 \times 10^{-4} \mathrm{~g}$ at baffle spacing of $100 \mathrm{~mm}$ and dosing rate of $0.55 \mathrm{ml} / \mathrm{s}$, while the relationship between outlet floc and dosing rate at $55.07 \mathrm{ml} / \mathrm{s}$ discharge indicate that vertical mixers are better at $250 \mathrm{~mm}$ baffle spacing having a maximum sediment deposition of $985 \times 10^{-4} \mathrm{~g}$ with a $0.95 \mathrm{ml} / \mathrm{s}$ dosing rate. For $60.34 \mathrm{ml} / \mathrm{s}$ discharge, the maximum sediment deposition was $307 \times 10^{-4} \mathrm{~g}$ at $250 \mathrm{~mm}$ spacing and 0.75 $\mathrm{ml} / \mathrm{s}$ dosing rate indicating that horizontal mixers are better. In $62.45 \mathrm{ml} / \mathrm{s}$ discharge, maximum sediment deposition was found to be $335 \times 10^{-4} \mathrm{~g}$ at $300 \mathrm{~mm}$ spacing and $0.95 \mathrm{ml} / \mathrm{s}$ dosing rate showing that horizontal mixers are better. Considering the performance of the tank at $63.27 \mathrm{ml} / \mathrm{s}$, maximum sediment deposit was $715 \times 10^{-4} \mathrm{~g}$ for a dosing rate of $0.35 \mathrm{ml} / \mathrm{s}$ when the baffle spacing $150 \mathrm{~mm}$ in which the result show that horizontal mixers are better. Response surface methodology (RSM) presented by Montgomery (2008) [29] was further used for the analysis of data in this study for 
more reliable inference because it optimized the responses of these three variables. After the analysis, it was observed that for the vertically placed baffles, the stationary points of response surface for discharge rate, baffle spacing and dosing rate are $80.56762847 \mathrm{ml} / \mathrm{s},-119.8510359 \mathrm{~mm}$ and $0.04965779 \mathrm{ml} / \mathrm{s}$, the negative value of $-119.8510359 \mathrm{~mm}$ baffle spacing is indicative that the lowest value of $100 \mathrm{~mm}$ should be recommended, while for horizontally placed baffles, it was $70.636018 \mathrm{ml} / \mathrm{s}, 332.864704 \mathrm{~mm}$ and $1.402526 \mathrm{ml} / \mathrm{s}$, however, these results indicate that horizontally placed baffle mixers are better than vertically placed baffle mixers. To the best of our knowledge and the literature available to us, no work has compared the efficiencies of horizontal and vertical baffles in sedimentation tank. The only work where we can make slight comparison was the work of Razmi et al. (2013) [27], where a baffle half way along its length decreases performance, while a baffle closer to its inlet, $\mathrm{s} / \mathrm{L}=0.15$ (i.e. $1.2 \mathrm{~m}$ from inlet for $8.0 \mathrm{~m}$ long tank) and with height $25-30 \%$ of water depth improves efficiency. It is worthy to note that $1.2 \mathrm{~m}$ distance from inlet in the study by Razmi et al. (2013) [27] is equivalent to $150 \mathrm{~mm}$ in our work in terms of baffle spacing from the inlet. This is evident in Table 6 where the distances of baffle from the inlet $100 \mathrm{~mm}, 200 \mathrm{~mm}$ and $150 \mathrm{~mm}$ for discharge rates of $48.75 \mathrm{ml} / \mathrm{s}$, $60.34 \mathrm{ml} / \mathrm{s}$ and $63.27 \mathrm{ml} / \mathrm{s}$ respectively gave an average value of $150 \mathrm{~mm}$ baffle distance from the inlet.

Table 1. Variation of dosing rate with inlet and outlet flocs. at discharge of $48.75 \mathrm{ml} / \mathrm{s}$.

\begin{tabular}{|c|c|c|c|c|c|c|c|c|c|c|c|c|}
\hline \multicolumn{13}{|c|}{$Q=48.75 \mathrm{ml} / \mathrm{s}$} \\
\hline \multirow{2}{*}{ Dosing rate $(\mathrm{ml} / \mathrm{s})$} & \multicolumn{6}{|c|}{ Vertical baffles } & \multicolumn{6}{|c|}{ Horizontal baffles } \\
\hline & 0.00 (control) & 0.15 & 0.35 & 0.55 & 0.75 & 0.95 & 0.00 (control) & 0.15 & 0.35 & 0.55 & 0.75 & 0.95 \\
\hline Floc. $c_{i}(g) \times 10^{-4}$ & 164.0 & 68.1 & 50.0 & 33.8 & 15.0 & 8.0 & 122 & 67.9 & 49.9 & 33.9 & 14.9 & 9.0 \\
\hline Baffle spacing (mm) & \multicolumn{6}{|c|}{ Floc. for vertical baffles $c_{0}(g) \times 10^{-4}$} & \multicolumn{6}{|c|}{ Floc. for horizontal baffles $c_{0}(g) \times 10^{-4}$} \\
\hline 100 & 164 & 160 & 155 & 158 & 163 & 168 & 122 & 184 & 204 & 333 & 200 & 208 \\
\hline 150 & 56 & 122 & 158 & 174 & 188 & 195 & 56 & 128 & 167 & 174 & 205 & 208 \\
\hline 200 & 45 & 83 & 120 & 124 & 104 & 192 & 45 & 124 & 126 & 125 & 154 & 200 \\
\hline 250 & 52 & 127 & 106 & 113 & 113 & 130 & 52 & 98 & 136 & 123 & 102 & 100 \\
\hline 300 & 56 & 78 & 86 & 101 & 92 & 99 & 56 & 88 & 106 & 110 & 112 & 109 \\
\hline Total & 373 & 570 & 625 & 670 & 660 & 784 & 331 & 622 & 739 & 865 & 681 & 825 \\
\hline Average & 75 & 114 & 125 & 134 & 132 & 157 & 67 & 124 & 148 & 173 & 136 & 165 \\
\hline
\end{tabular}

Table 2. Variation of dosing rate with inlet and outlet flocs. at discharge of $55.07 \mathrm{ml} / \mathrm{s}$.

\begin{tabular}{|c|c|c|c|c|c|c|c|c|c|c|c|c|}
\hline \multicolumn{13}{|c|}{$Q=55.07 \mathrm{ml} / \mathrm{s}$} \\
\hline \multirow{2}{*}{ Dosing rate $(\mathrm{ml} / \mathrm{s})$} & \multicolumn{6}{|c|}{ Vertical baffles } & \multicolumn{6}{|c|}{ Horizontal baffles } \\
\hline & 0.00 (control) & 0.15 & 0.35 & 0.55 & 0.75 & 0.95 & 0.00 (control) & 0.15 & 0.35 & 0.55 & 0.75 & 0.95 \\
\hline Floc. $c_{i}(g) \times 10^{-4}$ & 55.0 & 54.7 & 44.0 & 33.8 & 22.0 & 3.8 & 55 & 54.9 & 43.9 & 33.9 & 21.9 & 3.9 \\
\hline Baffle spacing (mm) & \multicolumn{6}{|c|}{ Floc. for vertical baffles $c_{0}(g) \times 10^{-4}$} & \multicolumn{6}{|c|}{ Floc. for horizontal baffles $c_{0}(g) \times 10^{-4}$} \\
\hline 100 & 55 & 189 & 167 & 190 & 170 & 174 & 55 & 260 & 167 & 202 & 197 & 138 \\
\hline 150 & 47 & 125 & 125 & 126 & 123 & 124 & 54 & 136 & 128 & 139 & 140 & 138 \\
\hline 200 & 47 & 83 & 156 & 164 & 171 & 159 & 54 & 182 & 179 & 189 & 196 & 190 \\
\hline 250 & 29 & 302 & 966 & 102 & 106 & 985 & 83 & 280 & 276 & 290 & 302 & 302 \\
\hline 300 & 30 & 153 & 166 & 152 & 146 & 139 & 30 & 101 & 99 & 101 & 98 & 101 \\
\hline Total & 469 & 852 & 1580 & 734 & 716 & 1580 & 276 & 959 & 849 & 921 & 933 & 869 \\
\hline Average & 42 & 170 & 316 & 146 & 143 & 316 & 55 & 192 & 170 & 184 & 187 & 174 \\
\hline
\end{tabular}

Table 3. Variation of dosing rate with inlet and outlet flocs. at discharge of $60.34 \mathrm{ml} / \mathrm{s}$.

\begin{tabular}{|c|c|c|c|c|c|c|c|c|c|c|c|c|}
\hline \multicolumn{13}{|c|}{$Q=60.34 \mathrm{ml} / \mathrm{s}$} \\
\hline \multirow{2}{*}{ Dosing rate $(\mathrm{ml} / \mathrm{s})$} & \multicolumn{6}{|c|}{ Vertical baffles } & \multicolumn{6}{|c|}{ Horizontal baffles } \\
\hline & 0.00 (control) & 0.15 & 0.35 & 0.55 & 0.75 & 0.95 & 0.00 (control) & 0.15 & 0.35 & 0.55 & 0.75 & 0.95 \\
\hline Floc. $c_{i}(g) \times 10^{-4}$ & 52.0 & 52.0 & 50.0 & 45.0 & 35.0 & 17.0 & 52.0 & 52.0 & 43.0 & 35.0 & 25.9 & 17.0 \\
\hline Baffle spacing (mm) & \multicolumn{6}{|c|}{ Floc. for vertical baffles $c_{0}(g) \times 10^{-4}$} & \multicolumn{6}{|c|}{ Floc. for horizontal baffles $c_{0}(g) \times 10^{-4}$} \\
\hline 100 & 52 & 150 & 149 & 152 & 155 & 161 & 52 & 167 & 165 & 162 & 170 & 178 \\
\hline 150 & 43 & 99 & 128 & 121 & 132 & 136 & 157 & 155 & 163 & 160 & 159 & 166 \\
\hline 200 & 40 & 89 & 111 & 124 & 133 & 136 & 143 & 200 & 231 & 204 & 307 & 236 \\
\hline
\end{tabular}




\begin{tabular}{ccccccccccccccc}
\hline 250 & 57 & 112 & 121 & 189 & 155 & 170 & 122 & 167 & 201 & 230 & 199 & 200 \\
\hline 300 & 57 & 99 & 121 & 174 & 138 & 153 & 117 & 232 & 198 & 204 & 248 & 219 \\
\hline Total & 249 & 549 & 630 & 760 & 713 & 756 & 591 & 921 & 958 & 960 & 1083 & 999 \\
\hline Average & 50 & 110 & 126 & 152 & 143 & 151 & 118 & 184 & 192 & 192 & 217 & 199 \\
\hline
\end{tabular}

Table 4. Variation of dosing rate with inlet and outlet flocs. at discharge of $62.45 \mathrm{ml} / \mathrm{s}$.

\begin{tabular}{|c|c|c|c|c|c|c|c|c|c|c|c|c|}
\hline \multicolumn{13}{|c|}{$Q=62.45 \mathrm{ml} / \mathrm{s}$} \\
\hline \multirow{2}{*}{ Dosing rate $(\mathrm{ml} / \mathrm{s})$} & \multicolumn{6}{|c|}{ Vertical baffles } & \multicolumn{6}{|c|}{ Horizontal baffles } \\
\hline & 0.00 (control) & 0.15 & 0.35 & 0.55 & 0.75 & 0.95 & 0.00 (control) & 0.15 & 0.35 & 0.55 & 0.75 & 0.95 \\
\hline Floc. $c_{i}(g) \times 10^{-4}$ & 45.0 & 46.0 & 37.0 & 30.0 & 19.0 & 10.4 & 45.0 & 45.0 & 38.0 & 29.0 & 19.1 & 10.3 \\
\hline Baffle spacing $(\mathrm{mm})$ & \multicolumn{6}{|c|}{ Floc. for vertical baffles $c_{0}(g) \times 10^{-4}$} & \multicolumn{6}{|c|}{ Floc. for horizontal baffles $c_{0}(g) \times 10^{-4}$} \\
\hline 100 & 45 & 88 & 109 & 110 & 118 & 135 & 45 & 156 & 169 & 169 & 180 & 177 \\
\hline 150 & 43 & 134 & 156 & 145 & 230 & 267 & 43 & 100 & 109 & 113 & 117 & 134 \\
\hline 200 & 47 & 94 & 126 & 125 & 200 & 107 & 47 & 176 & 186 & 155 & 206 & 167 \\
\hline 250 & 44 & 100 & 116 & 125 & 93 & 107 & 44 & 210 & 212 & 235 & 193 & 207 \\
\hline 300 & 30 & 82 & 99 & 119 & 110 & 122 & 30 & 222 & 311 & 253 & 254 & 335 \\
\hline Total & 209 & 416 & 606 & 624 & 751 & 738 & 209 & 864 & 987 & 925 & 950 & 1020 \\
\hline Average & 42 & 83 & 121 & 125 & 150 & 143 & 42 & 173 & 197 & 185 & 190 & 204 \\
\hline
\end{tabular}

Table 5. Variation of dosing rate with inlet and outlet flocs. at discharge of $63.27 \mathrm{ml} / \mathrm{s}$.

\begin{tabular}{|c|c|c|c|c|c|c|c|c|c|c|c|c|}
\hline \multicolumn{13}{|c|}{$Q=63.27 \mathrm{ml} / \mathrm{s}$} \\
\hline \multirow{2}{*}{ Dosing rate $(\mathrm{ml} / \mathrm{s})$} & \multicolumn{6}{|c|}{ Vertical baffles } & \multicolumn{6}{|c|}{ Horizontal baffles } \\
\hline & 0.00 (control) & 0.15 & 0.35 & 0.55 & 0.75 & 0.95 & 0.00 (control) & 0.15 & 0.35 & 0.55 & 0.75 & 0.95 \\
\hline Floc. $c_{i}(g) \times 10^{-4}$ & 52.0 & 45.0 & 35.7 & 27.9 & 18.3 & 8.5 & 45.0 & 44.9 & 35.9 & 27.9 & 18.3 & 8.4 \\
\hline Baffle spacing (mm) & \multicolumn{6}{|c|}{ Floc. for vertical baffles $c_{0}(g) \times 10^{-4}$} & \multicolumn{6}{|c|}{ Floc. for horizontal baffles $c_{0}(g) \times 10^{-4}$} \\
\hline 100 & 52 & 175 & 173 & 175 & 178 & 170 & 45 & 152 & 149 & 151 & 100 & 147 \\
\hline 150 & 205 & 141 & 136 & 128 & 127 & 128 & 136 & 695 & 715 & 681 & 711 & 678 \\
\hline 200 & 47 & 136 & 134 & 130 & 130 & 134 & 79 & 542 & 526 & 494 & 490 & 493 \\
\hline 250 & 302 & 207 & 201 & 201 & 187 & 200 & 83 & 337 & 331 & 319 & 317 & 331 \\
\hline 300 & 153 & 343 & 339 & 331 & 346 & 339 & 30 & 122 & 119 & 114 & 124 & 119 \\
\hline Total & 759 & 1002 & 983 & 974 & 968 & 971 & 373 & 1848 & 1840 & 1759 & 1742 & 1768 \\
\hline Average & 152 & 200 & 197 & 195 & 194 & 194 & 75 & 368 & 368 & 352 & 348 & 354 \\
\hline
\end{tabular}

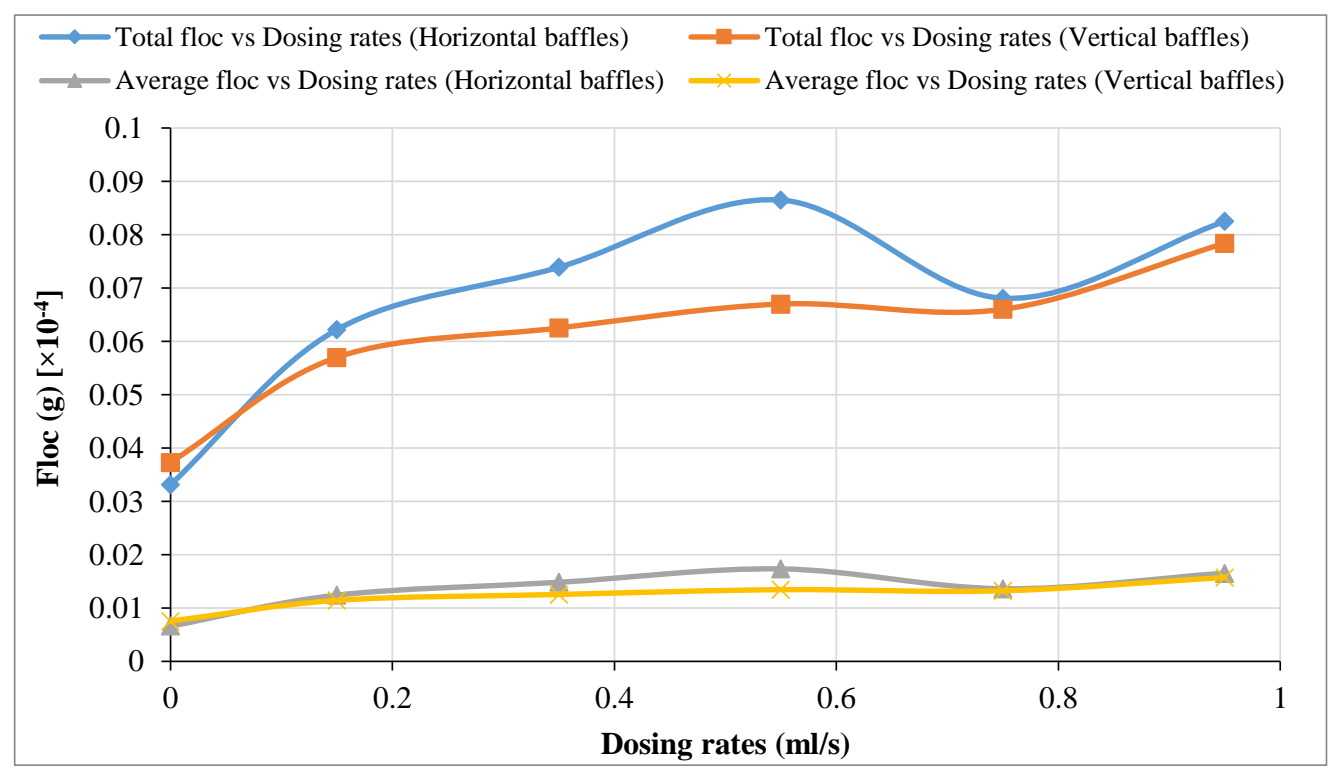

Figure 2. Variation of total and average floc with dosing rates for horizontally and vertically placed baffles at $48.75 \mathrm{ml} / \mathrm{s} \mathrm{discharge.}$ 


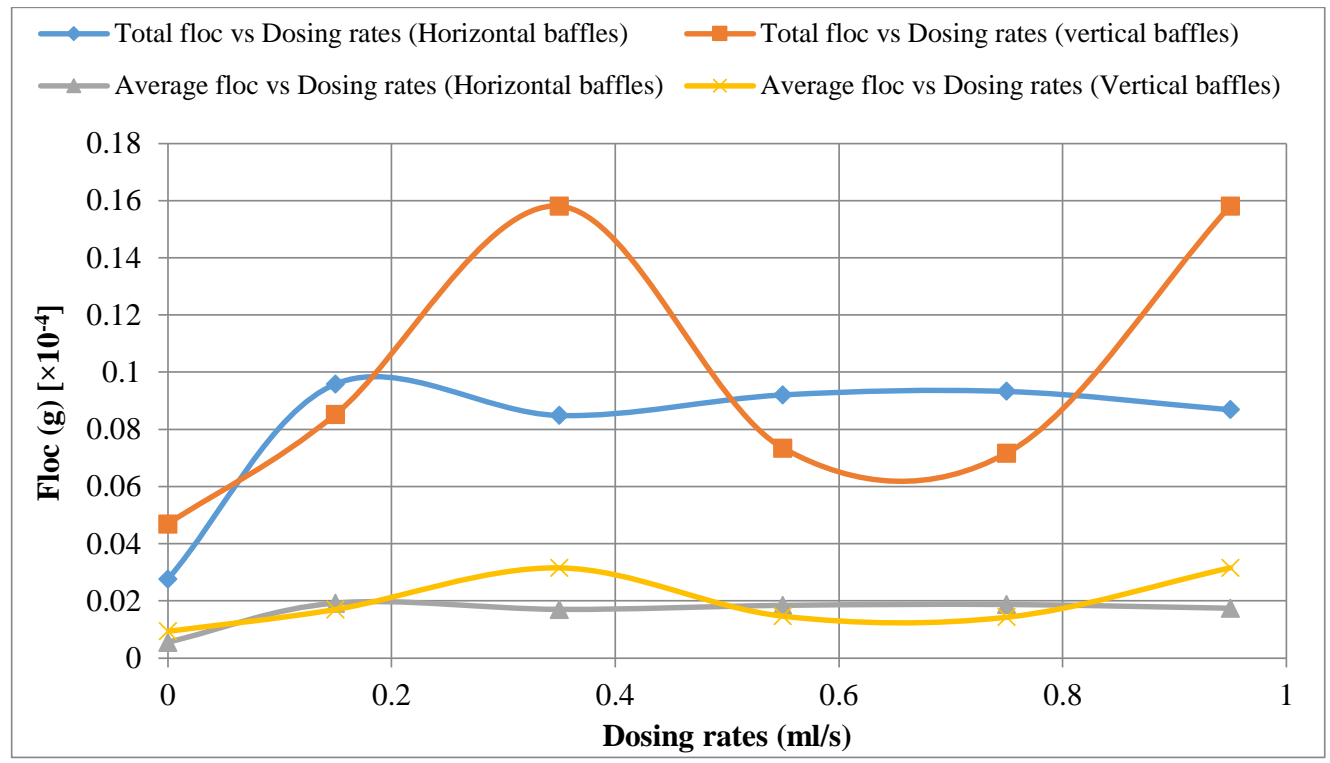

Figure 3. Variation of total and average floc with dosing rates for horizontally and vertically placed baffles at $55.07 \mathrm{ml} / \mathrm{s}$ discharge.

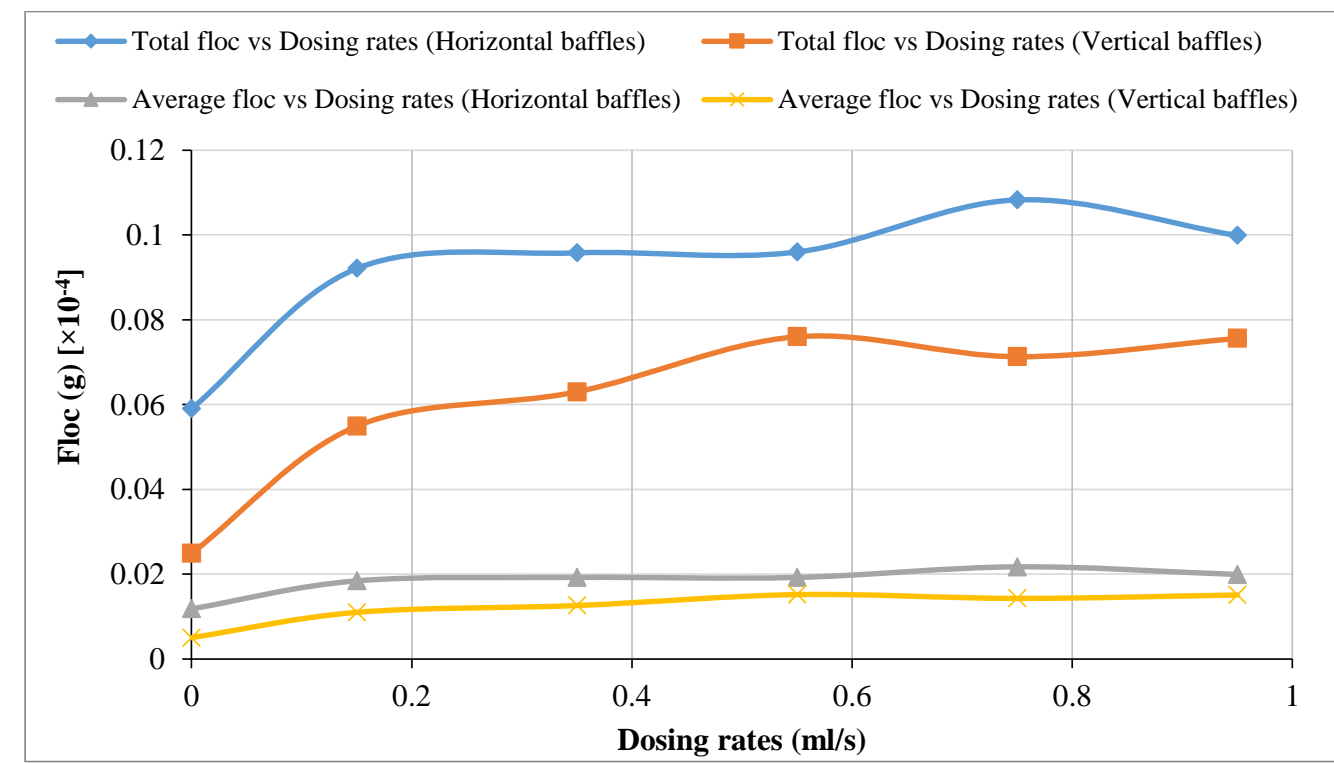

Figure 4. Variation of total and average floc with dosing rates for horizontally and vertically placed baffles at $60.34 \mathrm{ml} / \mathrm{s} \mathrm{discharge.}$

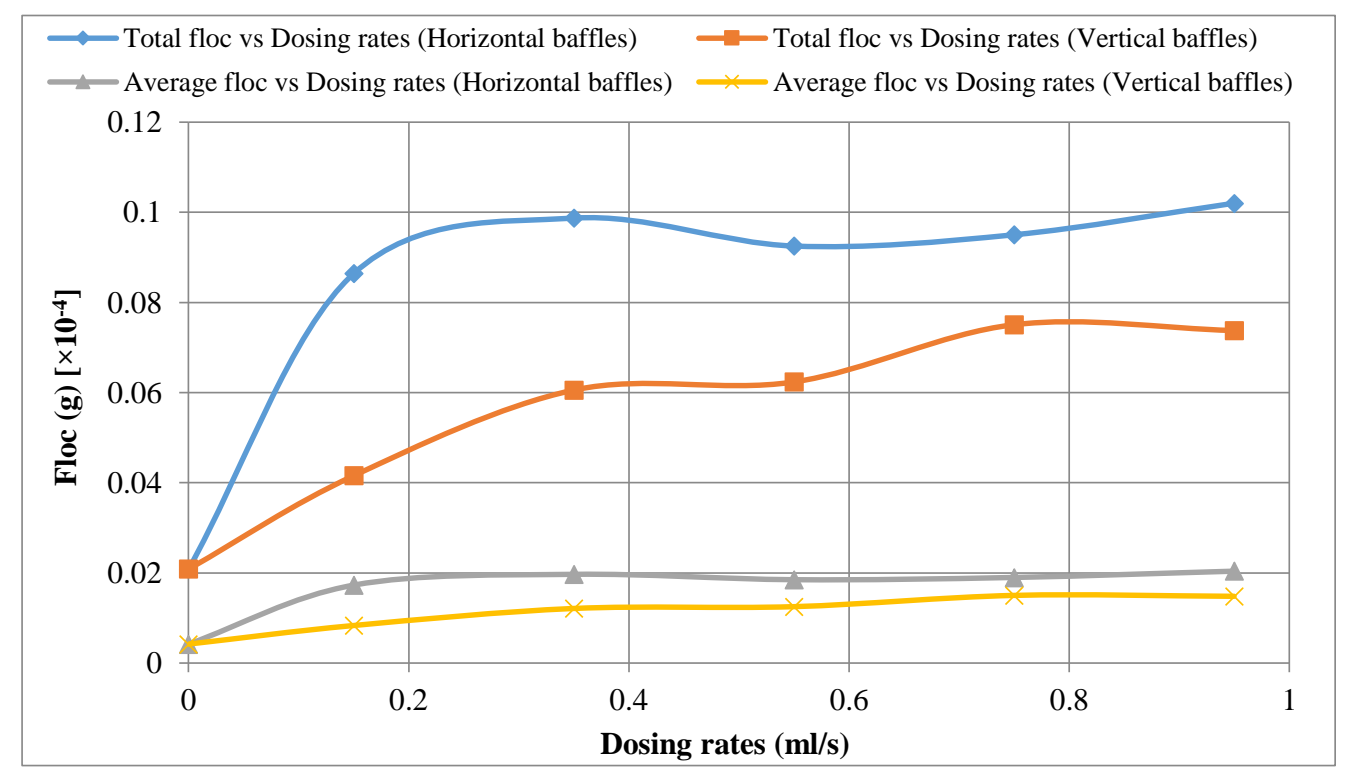

Figure 5. Variation of total and average floc with dosing rates for horizontally and vertically placed baffles at $62.45 \mathrm{ml} / \mathrm{s} \mathrm{discharge.}$ 


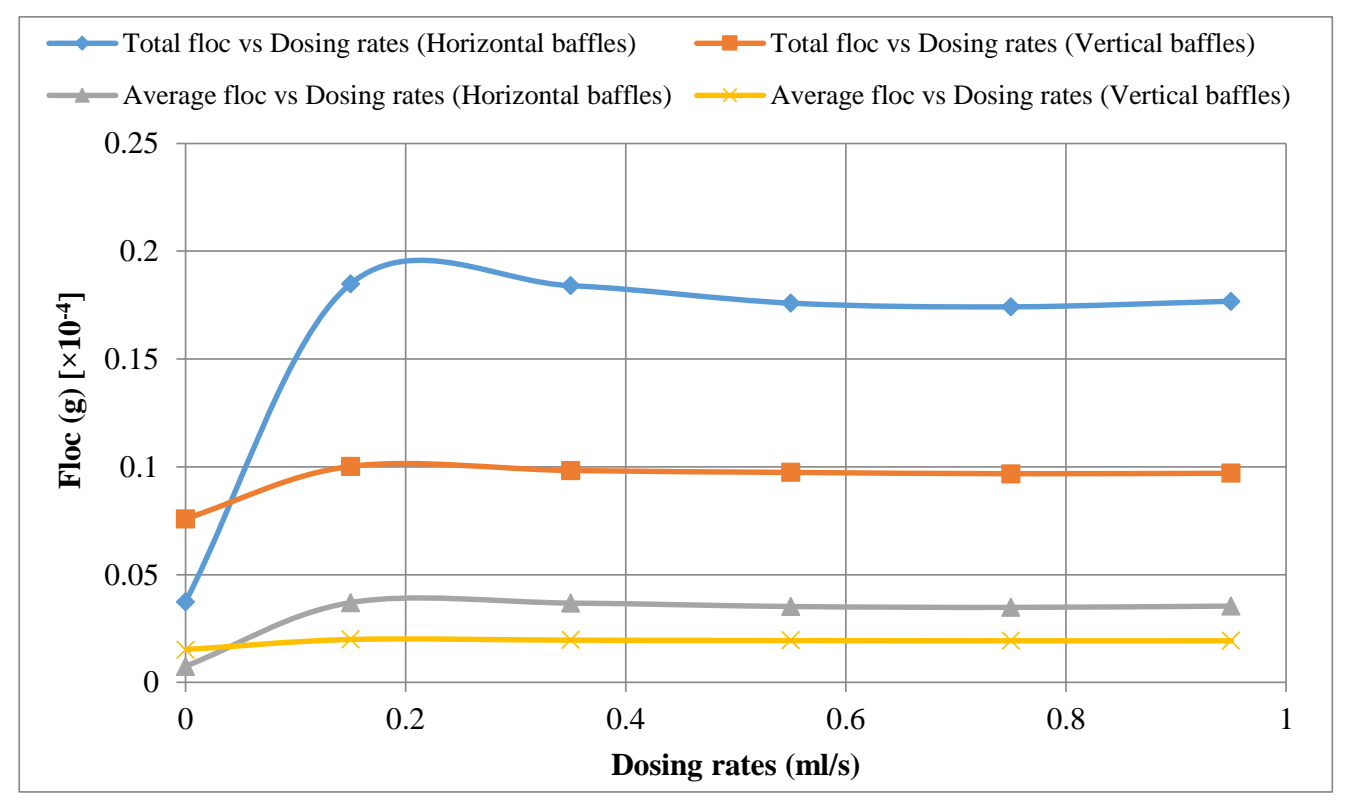

Figure 6. Variation of total and average floc with dosing rates for horizontal and vertical mixers at $63.27 \mathrm{ml} / \mathrm{s} \mathrm{discharge.}$

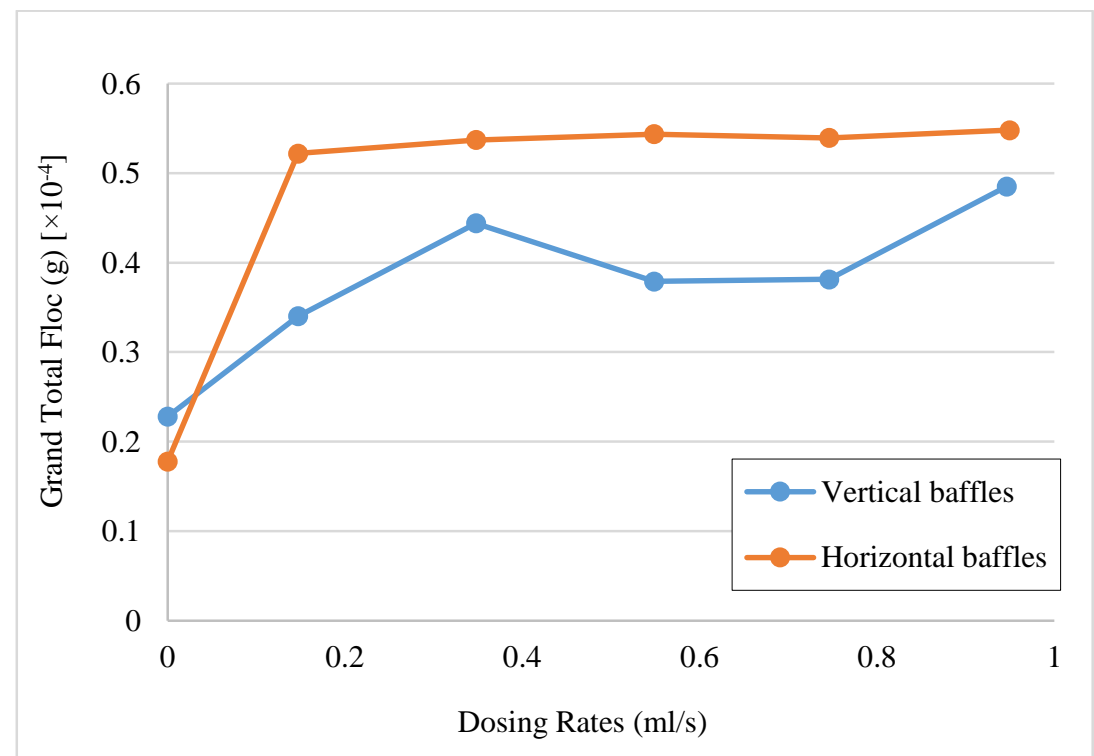

Figure 7. Variation of grand total floc with dosing rates.

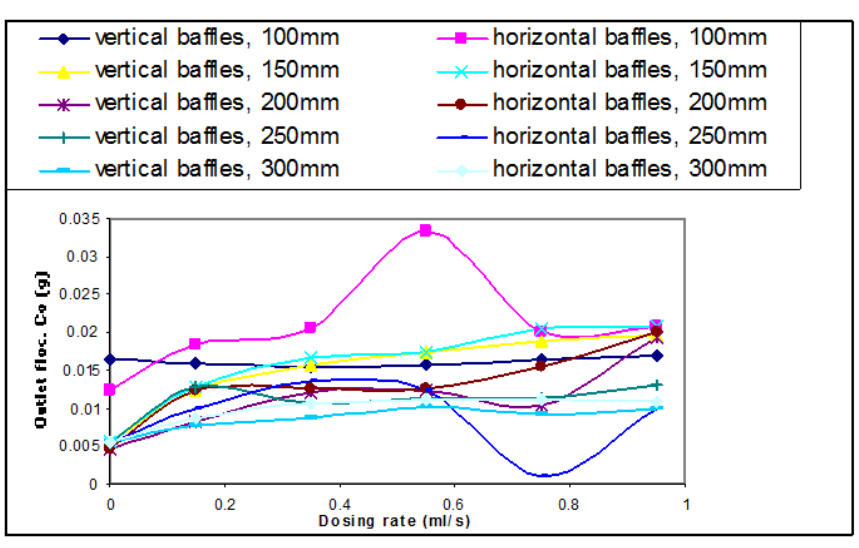

Figure 8. Variation of dosing rates with outlet floc at different baffle spacing for horizontal and vertical mixers at $48.75 \mathrm{ml} / \mathrm{s}$ discharge

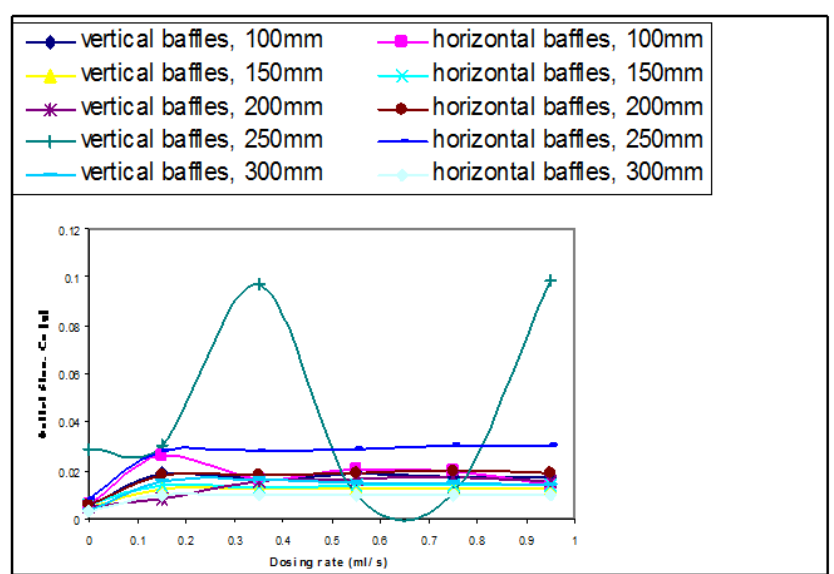

Figure 9. Variation of dosing rates with outlet floc at different spacing for horizontal and vertical mixers at $55.07 \mathrm{ml} / \mathrm{s}$ discharge. 


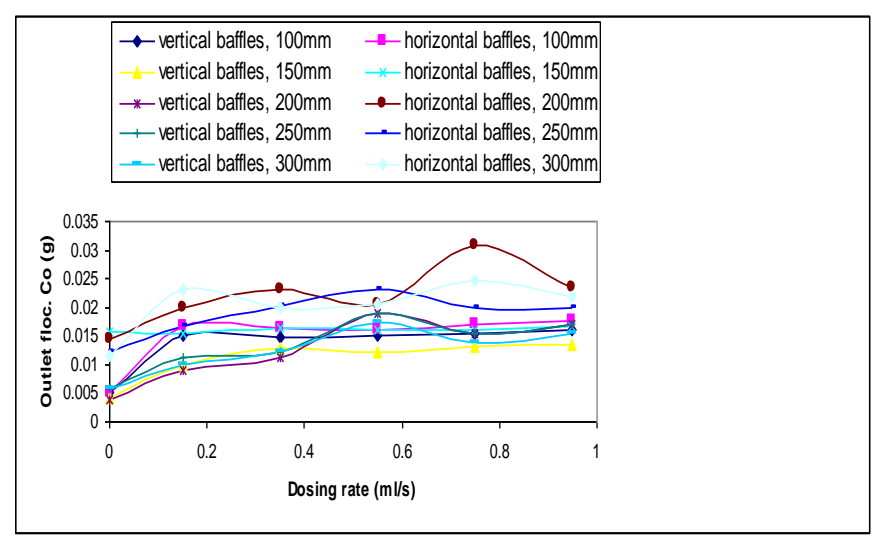

Figure 10. Variation of dosing rates with outlet floc at different baffle spacing for horizontal and vertical mixers at $60.34 \mathrm{ml} / \mathrm{s}$ discharge.

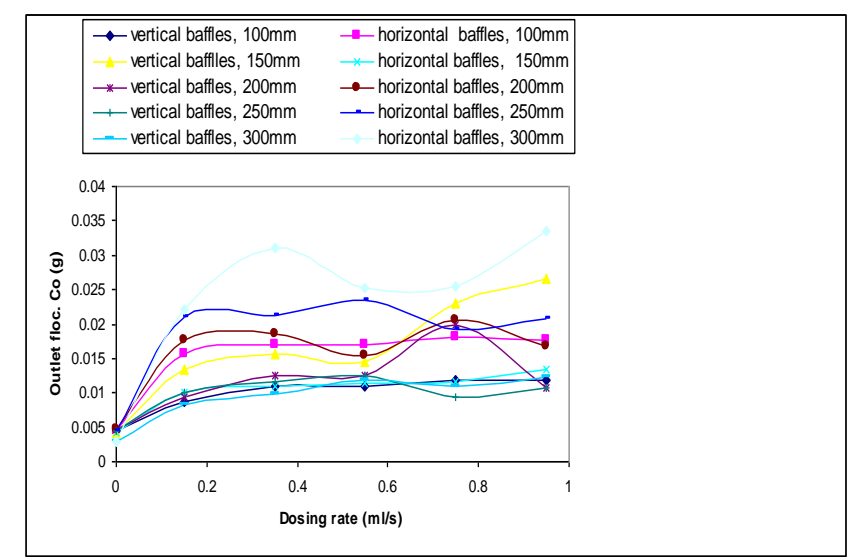

Figure 11. Variation of dosing rates with outlet floc at different spacing for horizontal and vertical mixers at 62.45 $\mathrm{ml} / \mathrm{s}$ discharge.

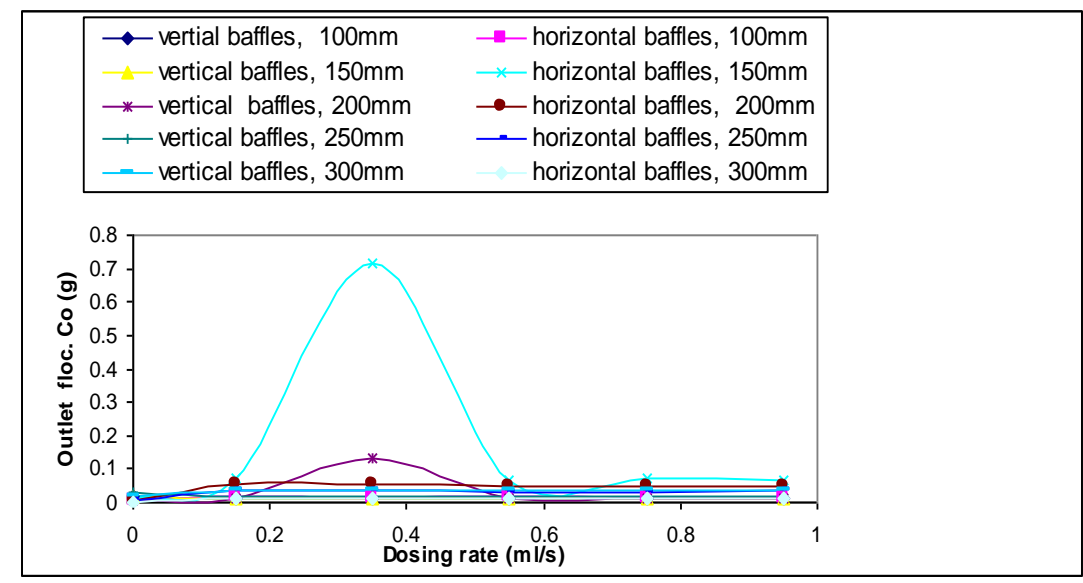

Figure 12. Variation of dosing rates with outlet floc at different baffle spacing for horizontal and vertical mixers at $63.27 \mathrm{ml} / \mathrm{s}$ discharge.

Table 6. Summary of results of Tables 1 to 5.

\begin{tabular}{ccccc}
\hline Discharge $(\mathbf{m l} / \mathbf{s})$ & Dosing rate $(\mathbf{m l} / \mathbf{s})$ & Baffle spacing $(\mathbf{m m})$ & ${\text { Maximum sediment } \mathbf{( g )} \times \mathbf{1 0}^{\mathbf{- 4}}}^{\text {Inference (better) }}$ \\
\hline 48.75 & 0.55 & 100 & 333 & Horizontal \\
\hline 55.07 & 0.95 & 250 & 985 & Vertical \\
\hline 60.34 & 0.75 & 250 & 307 & Horizontal \\
\hline 62.45 & 0.95 & 300 & 335 & Horizontal \\
\hline 63.27 & 0.35 & 150 & 715 & Horizontal \\
\hline
\end{tabular}

\section{The Horizontal Data Analysis}

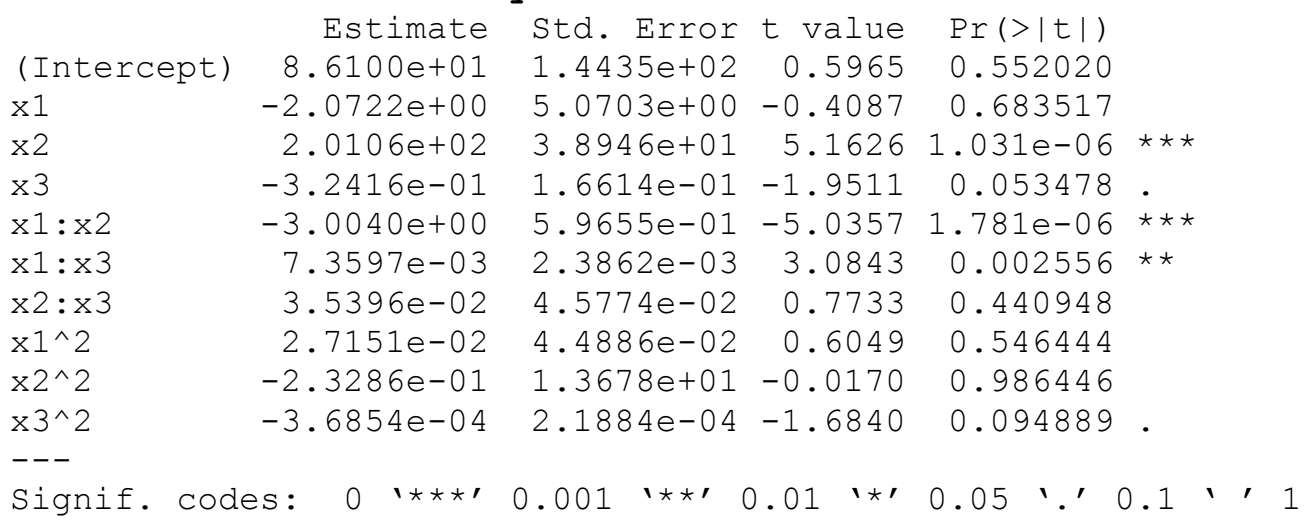

Multiple R-squared: $0.6009, \quad$ Adjusted R-squared: 0.5697 


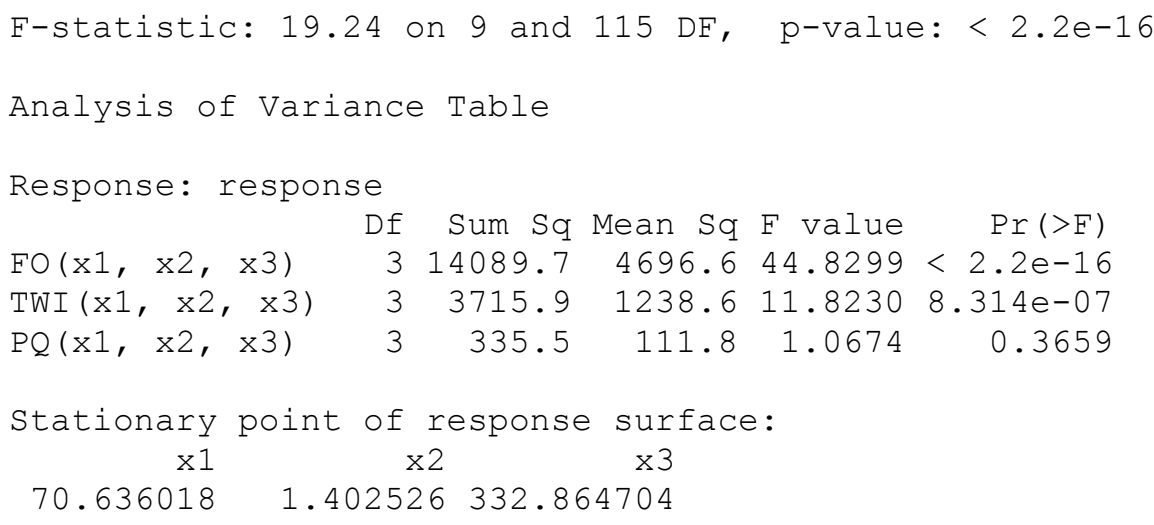

Eigen analysis:

\$values

[1] $1.4048373929-0.0002796582-1.6106323153$

\$vectors

$[, 1] \quad[, 2] \quad[, 3]$

$\begin{array}{llll}x 1 & 0.736924750 & 0.011370558 & 0.675879148\end{array}$

$\begin{array}{llll}x 2 & -0.675942728 & 0.002657424 & 0.736949365\end{array}$

x3 $-0.0065834290 .999931822-0.009644168$

What we see in the summary is the usual summary for a $1.0 \mathrm{~m}$ object (with a subtle difference), followed by some additional information particular to response surfaces. The subtle difference is that the labelling of the regression coefficients is simplified. The analysis-of-variance table shown includes a breakdown of lack of fit and pure error, and we are also given information about the direction of steepest ascent. In this particular example, the steepest-ascent information is of great use, because there is significant fit for this model $(p<0.01)$ for the first order. It suggests that for this work, a first order model may suffice. However, augmenting the first order model with a higher order model may produce a better optimum for the levels. For example, we could add two-way interactions and the quadratic terms as shown in the summary table:
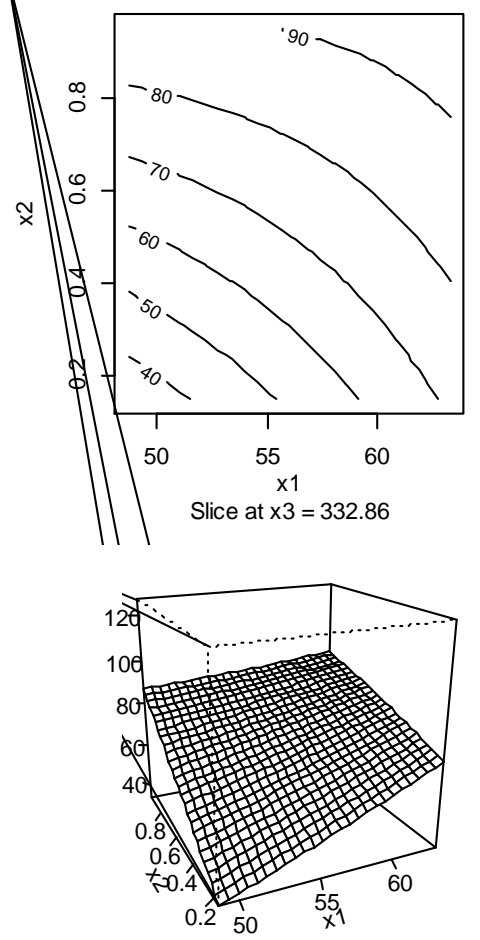

Slice at $\times 3=332.86$
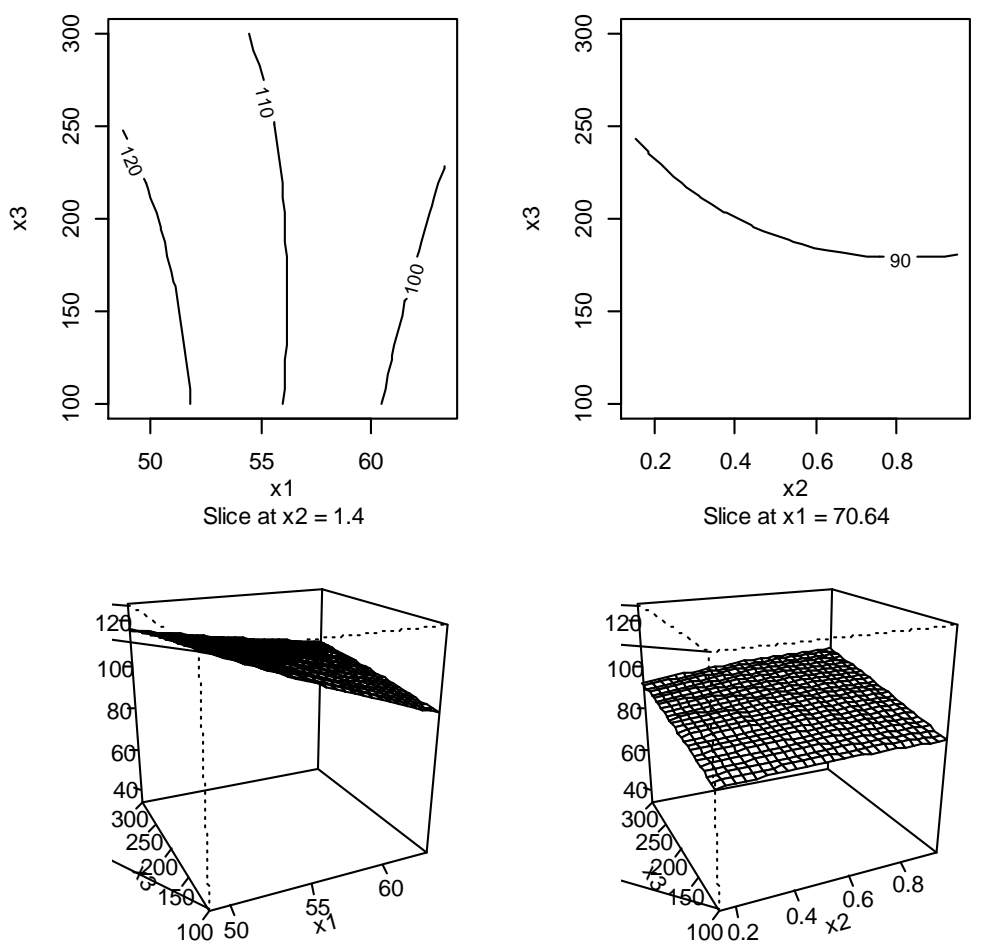

Figure 13. Contour and surface plots of $x 1, x 2$ and $x 3$ variables for horizontally fixed baffles. 
From the analysis of variance, it is clear again that the second-order (TWI and PQ) terms contribute slightly significantly to the model, so the canonical analysis maybe relevant in obtaining the maximum points. From the canonical values, the stationary point is fairly near the experimental region, since the Eigen values are of negative sign, indicating that it is a maximum. The residual analysis is also given by:

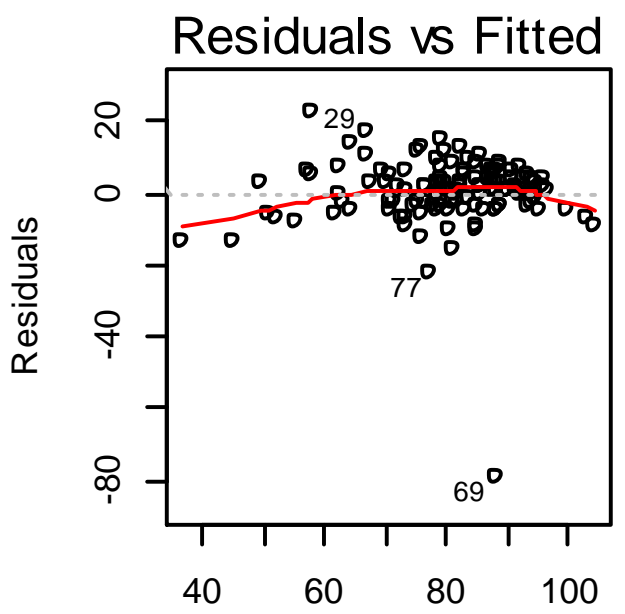

Fitted values

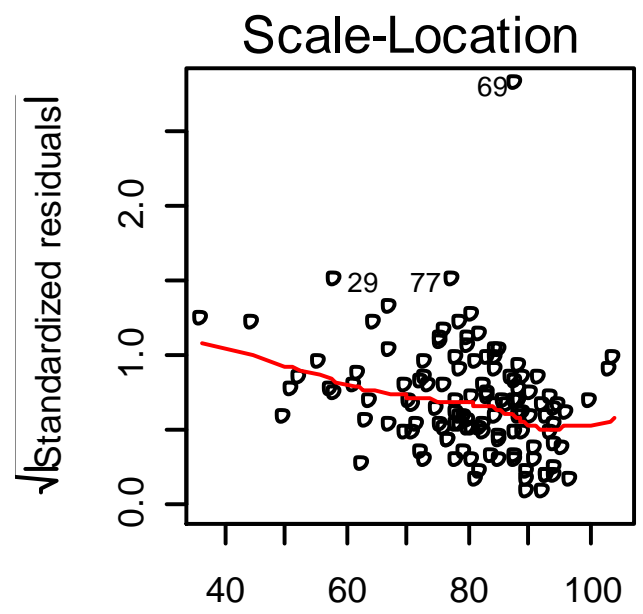

Fitted $v$ alues

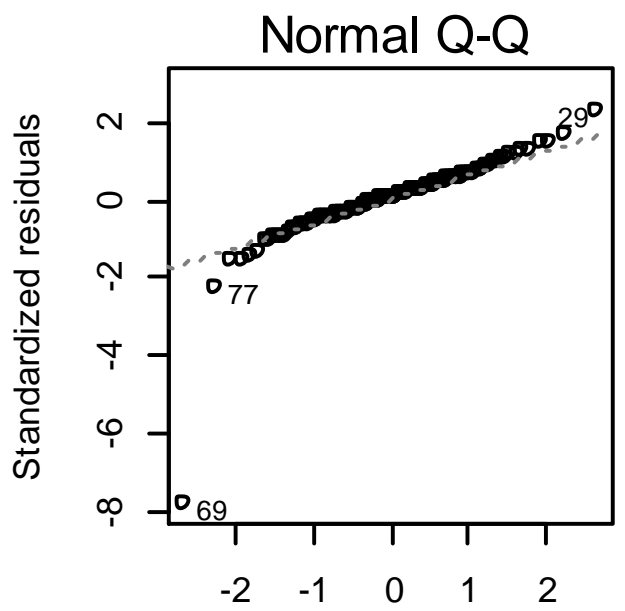

Theoretical Quantiles

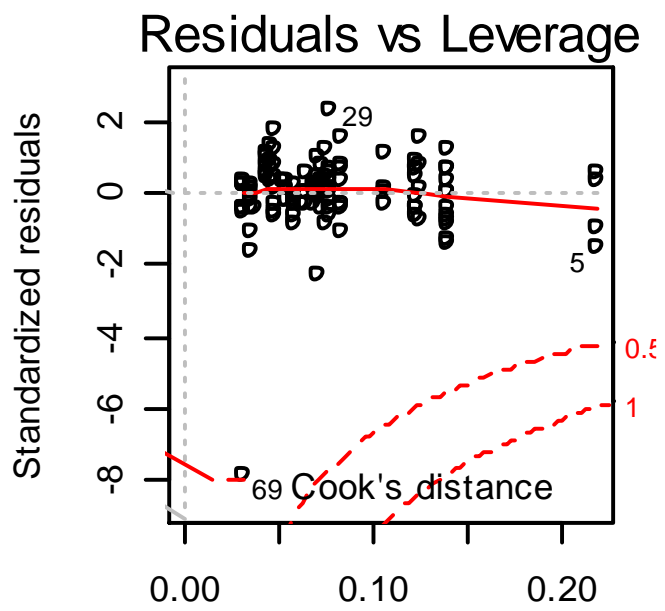

Lev erage

Figure 14. Residual plots of the model for horizontal baffles.

The Vertical Data Analysis

$\begin{array}{lrrrr} & \text { Estimate } & \text { Std. Error } & \text { value } & \text { Pr }(>|t|) \\ \text { (Intercept) } & 3.5055 e+01 & 1.3199 e+02 & 0.2656 & 0.791032 \\ \text { x1 } & 1.4949 e-01 & 4.6363 e+00 & 0.0322 & 0.974334 \\ \text { x2 } & 2.0039 e+02 & 3.5612 e+01 & 5.6270 & 1.311 e-07 \\ \text { x3 } & -4.5266 e-01 & 1.5192 e-01 & -2.9796 & 0.003522 \\ \text { x1:x2 } & -2.4423 e+00 & 5.4548 e-01 & -4.4773 & 1.791 e-05 \\ \text { x1:x3 } & 6.1729 e-03 & 2.1819 e-03 & 2.8291 & 0.005509 \\ \text { x2:x3 } & 1.7240 e-02 & 4.1856 e-02 & 0.4119 & 0.681189 \\ \text { x1^2 } & 4.4163 e-03 & 4.1044 e-02 & 0.1076 & 0.914501 \\ \text { x2^2 } & -1.5682 e+01 & 1.2507 e+01 & -1.2539 & 0.212429 \\ \text { x3^2 } & 1.8995 e-04 & 2.0011 e-04 & 0.9492 & 0.344486\end{array}$

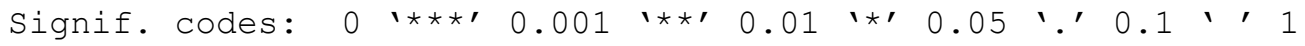

Multiple R-squared: $0.7048, \quad$ Adjusted R-squared: 0.6817

F-statistic: 30.5 on 9 and $115 \mathrm{DF}, \mathrm{p}$-value: $<2.2 \mathrm{e}-16$ 
Analysis of Variance Table

Response: response

$\begin{array}{lrrrrr} & \text { Df } & \text { Sum Sq } & \text { Mean Sq } F \text { value } & \text { Pr }(>F) \\ \text { FO }(x 1, x 2, x 3) & 3 & 21358.9 & 7119.6 & 81.2774<2.2 e-16 \\ \text { TWI }(x 1, x 2, x 3) & 3 & 2471.9 & 824.0 & 9.4065 & 1.309 e-05 \\ \text { PQ }(x 1, x 2, x 3) & 3 & 217.7 & 72.6 & 0.8283 & 0.4809 \\ \text { Residuals } & 115 & 10073.6 & 87.6 & & \\ \text { Lack of fit } & 115 & 10073.6 & 87.6 & & \\ \text { Pure error } & 0 & 0.0 & & \end{array}$

Stationary point of response surface:
80.56762847
$0.04965779-119.85103597$

Eigen analysis:

\$values
[1] $9.896774 e-02$
$1.359878 e-04-1.577664 e+01$

\$vectors

$$
[, 1] \quad[, 2] \quad[, 3]
$$

$\begin{array}{lllll}x 1 & 0.99672337 & -0.024298710 & -0.0771498093\end{array}$

$\begin{array}{lllll}x 2 & -0.07711320 & 0.002441587 & -0.9970193546\end{array}$

$\begin{array}{lllll}\times 3 & 0.02441465 & 0.999701761 & 0.0005598353\end{array}$

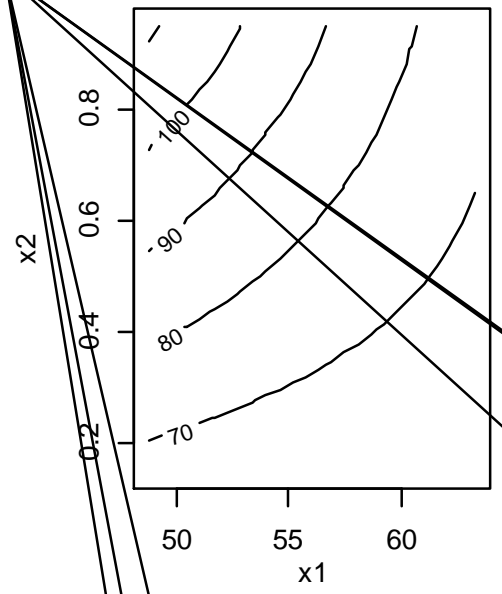

Slice at $x 3=-119.85$

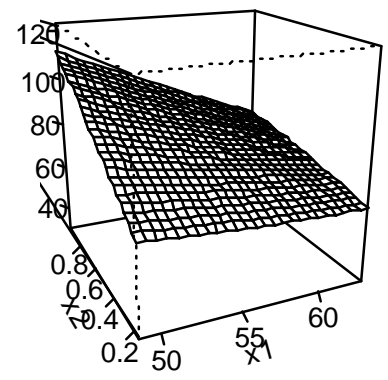

Slice at $\times 3=-119.85$

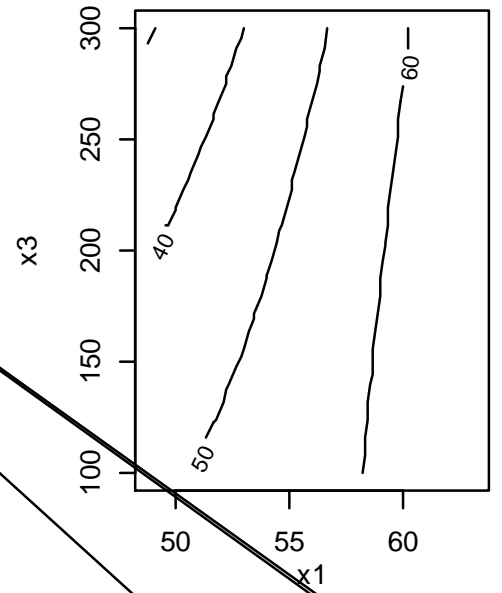

Slice at $x 2=0.05$

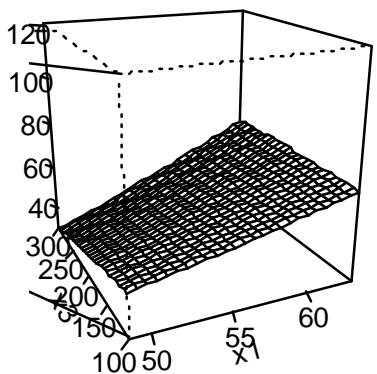

Slice at $\mathrm{x} 2=0.05$

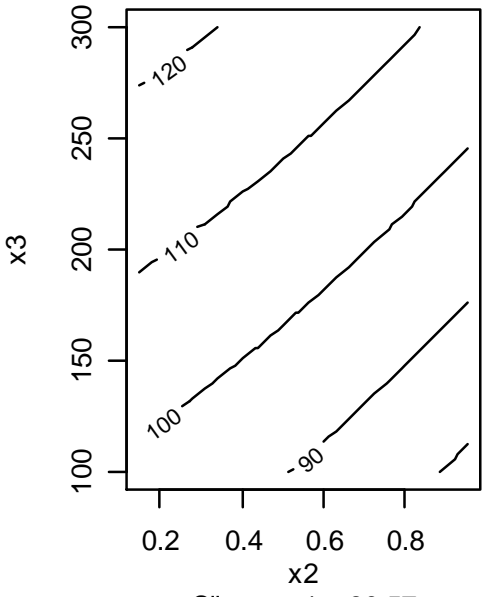

Slice at $x 1=80.57$

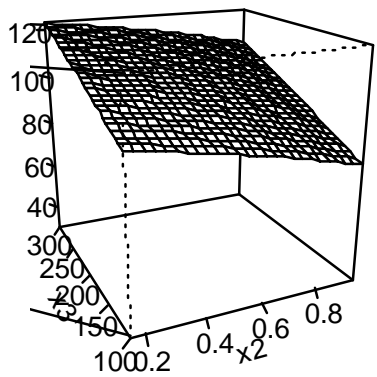

Slice at $\times 1=80.57$

Figure 15. Contour and surface plots of $x 1, x 2$ and $x 3$ variables for vertical baffles. 
The residual analysis is given by:

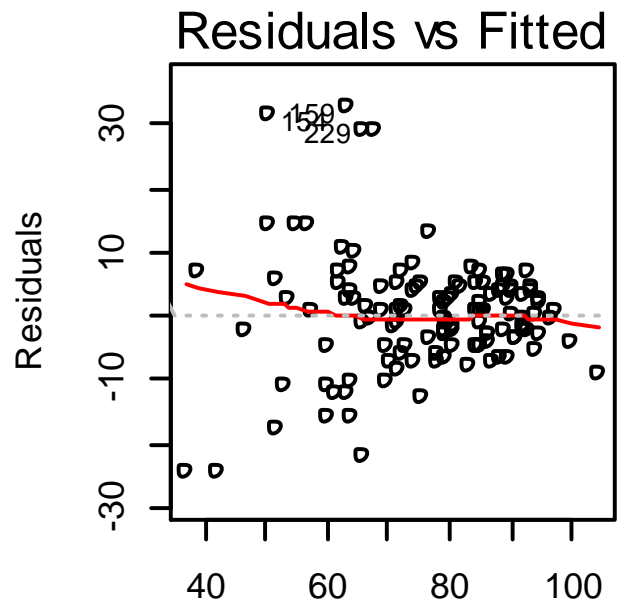

Fitted values

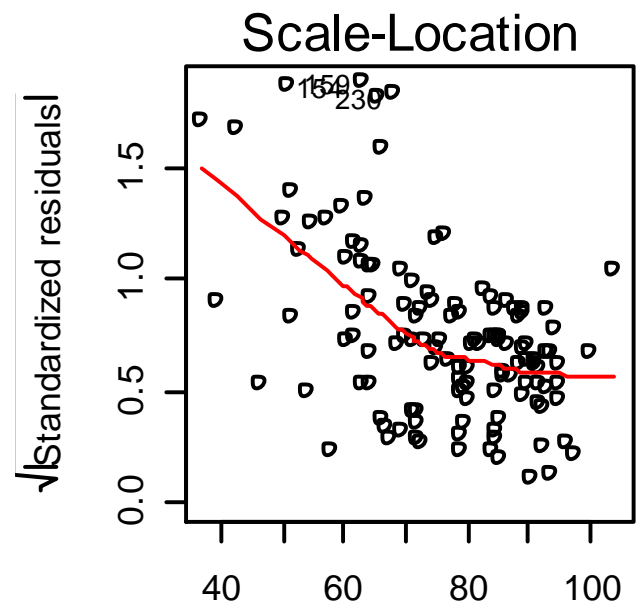

Fitted values

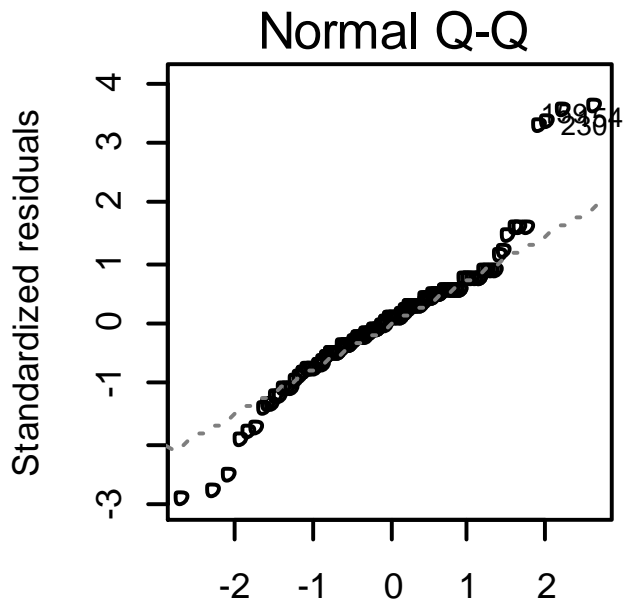

Theoretical Quantiles

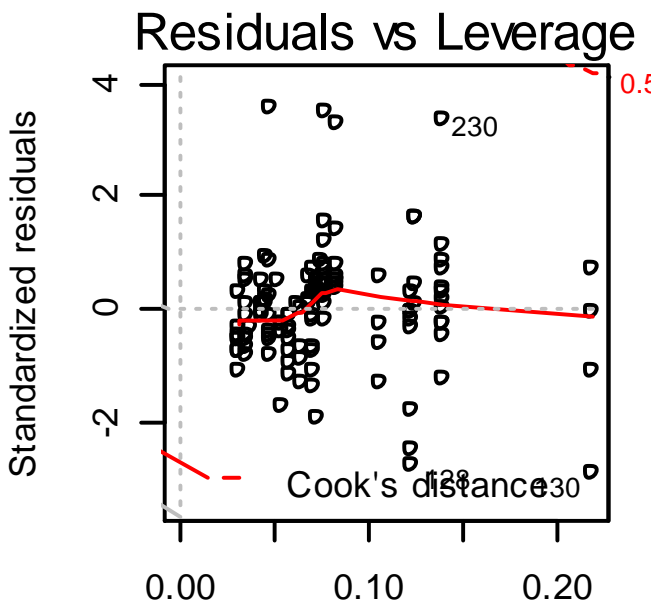

Lev erage

Figure 16. Residual plots of the model for vertical baffles.

\section{4- Conclusion}

From the analysis and the results associated with, it can be seen that horizontal baffles are better than vertical baffles. This is evident from the optimization of the responses of the three variables that controlled clarification in the sedimentation tanks by response surface methodology. Better result was achieved in the vertical baffle at discharge of $48.75 \mathrm{ml} / \mathrm{s}$, but horizontal baffles exhibited better clarification at discharges of $55.07 \mathrm{ml} / \mathrm{s}, 60.34 \mathrm{ml} / \mathrm{s}, 62.45 \mathrm{ml} / \mathrm{s}$, and $63.27 \mathrm{ml} / \mathrm{s}$. Grand total sediment/flocs at various dosing rates also favor horizontal baffles. Response surface methodology presented by Montgomery, 2008 further used for analyses of data in this study indicate that the stationary points of response surface for discharge, baffle distance from the inlet and dosing rates are $80.56762847 \mathrm{ml} / \mathrm{s}$, $100.000000 \mathrm{~mm}$ and $0.04965779 \mathrm{ml} / \mathrm{s}$ for vertical baffles. It was $70.636018 \mathrm{ml} / \mathrm{s}, 332.864704 \mathrm{~mm}$ and $1.402526 \mathrm{ml} / \mathrm{s}$ for horizontal baffles. It is true that the baffle distance of $332.864704 \mathrm{~mm}$ from inlet for horizontal baffles contradict with the work of Razmi et al. (2013) [27], however, results from the response surface which optimized the system revealed that horizontal baffles gave better performance than vertical baffles.

\section{5- Conflict of Interest}

The authors declare no conflict of interest. 


\section{6- References}

[1] Ahmed, F. H., A. Kamel, and S. Abdel Jawad. "Experimental determination of the optimal location and contraction of sedimentation tank baffles." Water, Air, and Soil Pollution 92, no. 3-4 (1996): 251-271. doi.10.1007/BF00283562.

[2] Krebs, Peter, Daniel Vischer, and Willi Gujer. "Inlet-structure design for final clarifiers." Journal of environmental engineering 121, no. 8 (1995): 558-564. doi:10.1061/(asce)0733-9372(1995)121:8(558).

[3] Metcalf, L., and H.P. Eddy. Wastewater Engineering: Treatment and reuse, 3rd Ed. McGraw-Hill Book Co. New York, 2003.

[4] Crosby, R.M. Evaluation of the hydraulic characteristics of activated sludge secondary clarifiers, Environmental Protection Agency, Office of Research and Development, Washington D.C., U.S. Report EPA/68-03-2782, USEPA, 1984.

[5] Taebi-Harandy, A. "Formation of Density Currents in Secondary Clarifier." Water Research 34, no. 4 (March 2000): 1225-1232. doi:10.1016/s0043-1354(99)00261-4.

[6] Rodríguez López, Patricia, Antonio Gutiérrez Lavín, Manuel M. Mahamud López, and Julio L. Bueno de las Heras. "Flow Models for Rectangular Sedimentation Tanks." Chemical Engineering and Processing: Process Intensification 47, no. 9-10 (September 2008): 1705-1716. doi:10.1016/j.cep.2007.09.020.

[7] Tamayol, A., B. Firoozabadi, and M. A. Ashjari. "Hydrodynamics of Secondary Settling Tanks and Increasing Their Performance Using Baffles." Journal of Environmental Engineering 136, no. 1 (January 2010): 32-39. doi:10.1061/(asce)ee.19437870.0000126 .

[8] Parvizi, Soroush, Eskandar Keshavarz Alamdari, Seyed Hasan Hashemabadi, Maryam Kavousi, and Anahita Sattari. "Investigating Factors Affecting on the Efficiency of Dynamic Mixers." Mineral Processing and Extractive Metallurgy Review 37, no. 5 (September 2, 2016): 342-368. doi:10.1080/08827508.2016.1218868.

[9] Tamayol, A., B. Firoozabadi, and G. Ahmadi, Determination of settling tanks performance using an Eulerian -Lagrangian method. Journal of Applied Fluid Mechanics, 1(1): 43-54, (2008).

[10] Ekama, G. A., G. L. Barnard, F. W. Gunthert, P. Krebs, J. A. McCorquodale, D. S. Parker, and E. J. Wahlberg. "Secondary settling tanks." London: International Association on Water Quality (1997).

[11] Goula, Athanasia M., Margaritis Kostoglou, Thodoris D. Karapantsios, and Anastasios I. Zouboulis. "A CFD Methodology for the Design of Sedimentation Tanks in Potable Water Treatment." Chemical Engineering Journal 140, no. 1-3 (July 2008): 110121. doi:10.1016/j.cej.2007.09.022.

[12] Manual on Water Supply and Treatment, Central Public Health and Environmental Engineering Organization, Ministry of Urban Development, Technology and Engineering - 741pp, India, 1999.

[13] Parker, D. S., D. J. Kinnear, and E. J. Wahlberg. "Review of folklore in design and operation of secondary clarifiers." Journal of Environmental Engineering 127, no. 6 (2001): 476-484. doi:10.1061/(asce)0733-9372(2001)127:6(476).

[14] Krebs, P., A.I. Stamou, J.L. Garcia-Heras, and W. Rodi. "Influence of Inlet and Outlet Configuration on the Flow in Secondary Clarifiers.” Water Science and Technology 34, no. 5-6 (1996). doi:10.1016/0273-1223(96)00622-1.

[15] Mccorquodale, John A., and Siping Zhou. "Effects of Hydraulic and Solids Loading on Clarifier Performance." Journal of Hydraulic Research 31, no. 4 (July 1993): 461-478. doi:10.1080/00221689309498870.

[16] Xanthos, Savvas, Minwei Gong, Krish Ramalingam, John Fillos, Alan Deur, Keith Beckmann, and John Alexander McCorquodale. "Performance Assessment of Secondary Settling Tanks Using CFD Modeling." Water Resources Management 25, no. 4 (March 16, 2010): 1169-1182. doi:10.1007/s11269-010-9620-1.

[17] Bretscher, Ulrich, Peter Krebs, and Willi H. Hager. "Improvement of flow in final settling tanks." Journal of Environmental Engineering 118, no. 3 (1992): 307-321. doi: 10.1061/(asce)0733-9372(1992)118:3(307).

[18] Krebs, P. “The Hydraulics of Final Settling Tanks.” Water Science and Technology 23, no. 4-6 (February 1991): $1037-1046$. doi:10.2166/wst.1991.0555.

[19] Celik, I., W. Rodi, and A.I. Stamou. Prediction of hydrodynamic characteristics of rectangular settling tanks. International Symposium of Refined Flow Modeling and Turbulence Measurements, Iowa, USA, pp. 641 - 651, 1985.

[20] Adams, Eric W., and Wolfgang Rodi. "Modeling flow and mixing in sedimentation tanks." Journal of Hydraulic Engineering 116, no. 7 (1990): 895-913. doi:10.1061/(ASCE)0733-9429(1990)116:7(895).

[21] Lyn, D. A., A. I. Stamou, and W. Rodi. "Density currents and shear-induced flocculation in sedimentation tanks." Journal of hydraulic Engineering 118, no. 6 (1992): 849-867. doi:10.1061/(ASCE)0733-9429(1992)118:6(849)

[22] Liu, Baicang, Jun Ma, Lin Luo, Yuhua Bai, Shutao Wang, and Jing Zhang. "Two-dimensional LDV measurement, modeling, and optimal design of rectangular primary settling tanks." Journal of Environmental Engineering 136, no. 5 (2009): $501-507$. doi:10.1061/(ASCE)EE.1943-7870.0000186. 
[23] FlowScience, Flow-3D user manual; excellence in flow modeling software, v8.2, Santa Fe, New Mexico, USA, 2003.

[24] Rostami, Fatemeh, Mahdi Shahrokhi, Md Azlin Md Said, Rozi Abdullah, and Syafalni. "Numerical Modeling on Inlet Aperture Effects on Flow Pattern in Primary Settling Tanks.” Applied Mathematical Modelling 35, no. 6 (June 2011): 3012-3020. doi:10.1016/j.apm.2010.12.007.

[25] Shahrokhi, Mahdi, Fatemeh Rostami, Md Azlin Md Said, Saeed Reza Sabbagh Yazdi, and Syafalni. "The Effect of Number of Baffles on the Improvement Efficiency of Primary Sedimentation Tanks." Applied Mathematical Modelling 36, no. 8 (August 2012): 3725-3735. doi:10.1016/j.apm.2011.11.001.

[26] Shahrokhi, Mahdi, Fatemeh Rostami, Md Azlin Md Said, Saeid-Reza Sabbagh-Yazdi, Syafalni Syafalni, and Rozi Abdullah. "The Effect of Baffle Angle on Primary Sedimentation Tank Efficiency." Canadian Journal of Civil Engineering 39, no. 3 (March 2012): 293-303. doi:10.1139/12012-002.

[27] Razmi, A.M., R. Bakhtyar, B. Firoozabadi, and D.A. Barry. "Experiments and Numerical Modeling of Baffle Configuration Effects on the Performance of Sedimentation Tanks." Canadian Journal of Civil Engineering 40, no. 2 (February 2013): 140150. doi:10.1139/cjce-2012-0176.

[28] British Standard 1377, Method of test for soils for civil engineering purposes, British Standards Institution, London, 1975.

[29] Montgomery, D.C. Statistical quality control: A Modern Introduction, New York: John Wiley \& Sons, 2008.

[30] R Core Team (2017). R: A language and environment for statistical computing. R Foundation for Statistical Computing, Vienna, Austria. URL https:/www.R-project.org/. 